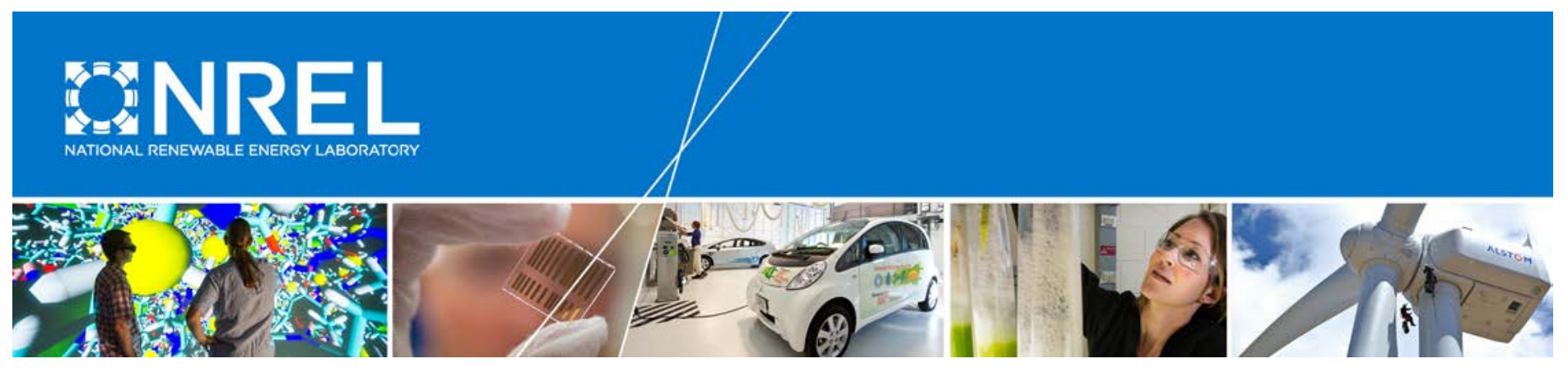

\title{
Impact of Clean Energy R\&D on the U.S. Power Sector
}

Paul Donohoo-Vallett U.S. Department of Energy

Trieu Mai, Matthew Mowers, and Gian Porro National Renewable Energy Laboratory

NREL is a national laboratory of the U.S. Department of Energy Office of Energy Efficiency \& Renewable Energy Operated by the Alliance for Sustainable Energy, LLC

This report is available at no cost from the National Renewable Energy Laboratory (NREL) at www.nrel.gov/publications.

Technical Report

NREL/TP-6A20-67691

January 2017

Contract No. DE-AC36-08G028308 


\section{Impact of Clean Energy R\&D on the U.S. Power Sector}

Paul Donohoo-Vallett

U.S. Department of Energy

Trieu Mai, Matthew Mowers, and Gian Porro National Renewable Energy Laboratory

Prepared under Task No. SA15.1019
NREL is a national laboratory of the U.S. Department of Energy Office of Energy Efficiency \& Renewable Energy Operated by the Alliance for Sustainable Energy, LLC

This report is available at no cost from the National Renewable Energy Laboratory (NREL) at www.nrel.gov/publications.

\section{Technical Report}

NREL/TP-6A20-67691

January 2017

Contract No. DE-AC36-08G028308
National Renewable Energy Laboratory 15013 Denver West Parkway 303-275-3000 • www.nrel.gov 


\section{NOTICE}

This report was prepared as an account of work sponsored by an agency of the United States government. Neither the United States government nor any agency thereof, nor any of their employees, makes any warranty, express or implied, or assumes any legal liability or responsibility for the accuracy, completeness, or usefulness of any information, apparatus, product, or process disclosed, or represents that its use would not infringe privately owned rights. Reference herein to any specific commercial product, process, or service by trade name, trademark, manufacturer, or otherwise does not necessarily constitute or imply its endorsement, recommendation, or favoring by the United States government or any agency thereof. The views and opinions of authors expressed herein do not necessarily state or reflect those of the United States government or any agency thereof.

This report is available at no cost from the National Renewable Energy Laboratory (NREL) at www.nrel.gov/publications.

Available electronically at SciTech Connect http:/www.osti.gov/scitech

Available for a processing fee to U.S. Department of Energy and its contractors, in paper, from:

U.S. Department of Energy

Office of Scientific and Technical Information

P.O. Box 62

Oak Ridge, TN 37831-0062

OSTI http://www.osti.gov

Phone: 865.576.8401

Fax: 865.576.5728

Email: reports@osti.gov

Available for sale to the public, in paper, from:

U.S. Department of Commerce

National Technical Information Service

5301 Shawnee Road

Alexandria, VA 22312

NTIS http://www.ntis.gov

Phone: 800.553 .6847 or 703.605 .6000

Fax: 703.605.6900

Email: orders@ntis.gov 


\section{Acknowledgments}

Our analysis relied on the research completed in the U.S. Department of Energy (DOE) report titled "Energy $\mathrm{CO}_{2}$ Emissions Impacts of Clean Energy Technology Innovation and Policy" (DOE 2017) and could not have been completed without the modeling assessment conducted as part of that study. We especially thank the people who developed and produced the initial analytical results which are used in this study, including Carla Frisch, Caitlin Murphy, Sarah Garman, Elke Hodson, and Aaron Bergman from the DOE Office of Energy Policy and Systems Analysis, along with Francis Wood and Sharon Showalter of OnLocation, Inc.

Multiple people assisted in developing the technology cost and performance inputs for the Advanced Technology Case used for the DOE (2017) study and leveraged in our analysis, including Sam Baldwin, Hoyt Battey, Gil Bindewald III, Alicia Birky, Nicholas Bleich, Matt Bowen, Erin Boyd, Lauren Boyd, Steve Capanna, Joe Cresko, Sarah Garman, Patrick Gilman, Michael Goff, David Gohlke, Judi Greenwald, Marcos Gonzalez Harsha, Zia Haq, Rebecca Jones-Albertus, Fred Joseck, Jordan Kislear, Alison LaBonte, Valri Lightner, Alicia Lindauer, Seungwook (Ookie) Ma, Jonathan Male, Jack Mayernik, Jim Moore, Rachael Nealer, Valerie Nubbe, Tien Nguyen, Franklin Orr, Bill Parks, Kara Podkaminer, Daniel Rabon, Timothy Reinhardt, David Rosner, Ann Satsangi, Sunita Satyapal, Tarak Shah, Sharon Showalter, Cody Taylor, Rich Tusing, Brian Walker, Jacob Ward, Brad Williams, Timothy Welch, and Charles Zelek at DOE; Erin Boedecker, Mindi Farber-DeAnda, John Maples, Cara Marcy, Chris Namovicz, and Jim Turnure from the U.S. Energy Information Administration; Aymeric Rousseau from Argonne National Laboratory; Kristin Gerdes from the National Energy Technology Laboratory; and Stuart Cohen, Eric Lantz, and Anna Wall from the National Renewable Energy Laboratory.

We thank multiple reviewers for their helpful comments and technical review of this document. Reviewers included Steve Capanna, Rebecca Jones-Albertus, Caitlyn Murphy, Kara Podkaminer, Lidija Sekaric, Rich Tusing, Brian Walker, and Brad Williams of the DOE; Cara Marcy and Chris Namovicz of the Energy Information Administration; John Bistline and David Young of the Electric Power Research Institute; and Doug Arent, Kevin Carroll, Eric Lantz, Jeff Logan, Dave Mooney, Robin Newmark, Gian Porro, and Dan Steinberg of the National Renewable Energy Laboratory. We also thank Mike Meshek and Mary Lukkonen for editorial support. We are grateful to Steve Capanna of the DOE for his support of this study. This research was funded by the U.S. DOE under contract number DE-AC36-08GO28308. Of course, any errors or omissions are the sole responsibility of the authors. 


\section{Executive Summary}

The U.S. government, along with other governments, private corporations and organizations, invests significantly in research, development, demonstration and deployment (RDD\&D) activities in clean energy technologies, in part to achieve the goal of a clean, secure, and reliable energy system. While specific outcomes and breakthroughs resulting from RDD\&D investment are unpredictable, it can be instructive to explore the potential impacts of clean energy RDD\&D activities in the power sector and to place those impacts in the context of current and anticipated market trends.

This analysis builds on and leverages analysis by the U.S. Department of Energy (DOE) titled "Energy $\mathrm{CO}_{2}$ Emissions Impacts of Clean Energy Technology Innovation and Policy" (DOE 2017). Similar to DOE (2017), we explore how additional improvements in cost and performance of clean energy technologies could impact the future U.S. energy system; however, unlike the economy-wide modeling used in DOE (2017) our analysis is focused solely on the electricity sector and applies a different and more highly spatially-resolved electric sector model. More specifically, we apply a scenario analysis approach to explore how assumed further advancements in clean electricity technologies would impact power sector generation mix, electricity system costs, and power sector carbon dioxide $\left(\mathrm{CO}_{2}\right)$ emissions.

For this exploration, we model a limited range of "what-if" RDD\&D and electricity policy conditions similar to those from DOE (2017). As a proxy for successful RDD\&D investments, we use a set of input assumptions for electricity-generating and end-use technologies to generate an Advanced Technology Case that reflects the technology targets developed by the U.S. DOE's Applied Energy Technology Offices as of October 2016. ${ }^{1}$ These targets are developed through a series of different methodologies (DOE 2017), such as bottom-up engineering studies and technology expert elicitations. ${ }^{2}$

In addition and similar to DOE (2017), we model a set of $\mathrm{CO}_{2}$ emissions policy scenarios layered on top of the Advanced Technology Case to examine the impact of technology advancement in comparison to and in combination with potential future $\mathrm{CO}_{2}$ emissions policies. As proxies for generic $\mathrm{CO}_{2}$ policies, these scenarios include initial $\mathrm{CO}_{2}$ prices of $\$ 10 /$ metric ton and $\$ 20 /$ metric ton in 2017 - escalating at $5 \%$ per year in real terms. ${ }^{3}$

We compare the resulting Advanced Technology Case deployment projections and associated impacts with a Base Case, both with and without $\mathrm{CO}_{2}$ prices. The Base Case assumes a businessas-usual trajectory which represents moderate RDD\&D successes for clean energy technologies. We also compare scenario results to the NREL 2016 Standard Scenarios (Cole, Mai et al. 2016) range of outcomes, which place the RDD\&D impacts in a broader outcome space based on an

\footnotetext{
${ }^{1}$ Our Advanced Technology Case relies on technology projections developed by the following U.S. DOE Offices: the Office of Energy Efficiency and Renewable Energy, Office of Fossil Energy, Office of Nuclear Energy, Office of Electricity Delivery and Energy Reliability.

${ }^{2}$ The different methods could result in different levels of optimism across technologies. We do not assess the full sensitivity space around all technology reduction possibilities nor the probability of achieving the assumed targets. ${ }^{3}$ Under this escalation, the initial \$10/metric ton and \$20/metric ton prices reach $\$ 50 /$ metric ton and $\$ 100 /$ metric ton, respectively, by 2050 .
} 
array of scenario sensitivities related to electricity demand growth, future fuel prices, and capacity retirements.

This analysis is intended to assess the potential electric system impact of one possible robust and successful portfolio of clean energy technology RDD\&D activities. The Advanced Technology Case represents significant technology advances for all clean generation and energy efficiency technologies and assumes that all these advances occur. This analysis does not examine the impact of other possible portfolios, or of advancement of only individual technologies or subset combinations of technologies, and is not meant to inform decisions on the make-up of future RDD\&D portfolios.

Key results from this analysis include the following:

1. Assumed RDD\&D-enabled clean energy technology cost reductions could lead to renewable generation as the largest source of electricity by 2050 under scenarios with and without $\mathrm{CO}_{2}$ prices (Figure ES-1). The Advanced Technology Case with no $\mathrm{CO}_{2}$ price results in over 2,200 terawatt-hours ( $\mathrm{TWh}$ ) of total renewable energy generation by 2050 (50\% of total generation), compared with just over 500 TWh in 2015 (14\% of total generation). This result suggests that if RDD\&D successfully achieves the clean energy technology cost projections represented in the Advanced Technology Case, renewable generation may see significant and sustained increases without new state or federal renewable or clean energy subsidies or mandates beyond existing policies. With the more moderate renewable energy technology cost reductions assumed in the Base Case and in the absence of additional policy, renewable electricity is anticipated to grow at a slower pace, reaching 1,600 TWh by 2050 (31\% of total generation).

However, a $\$ 10 /$ ton initial $\mathrm{CO}_{2}$ price (and then rising with time) coupled with Base Case technology assumptions is found to drive renewable generation to a similar or even greater level by 2050 level as in the Advanced Technology Case. Renewable generation's fractional share of total generation when a $\$ 10 /$ ton initial $\mathrm{CO}_{2}$ price is coupled with Base Case technology assumptions, however, is less than in the Advanced Technology Case, which included greater adoption of energy efficiency measures. Further increases in assumed $\mathrm{CO}_{2}$ prices do not substantially increase the generation of renewables in the long-term but are found to accelerate renewable deployment. 

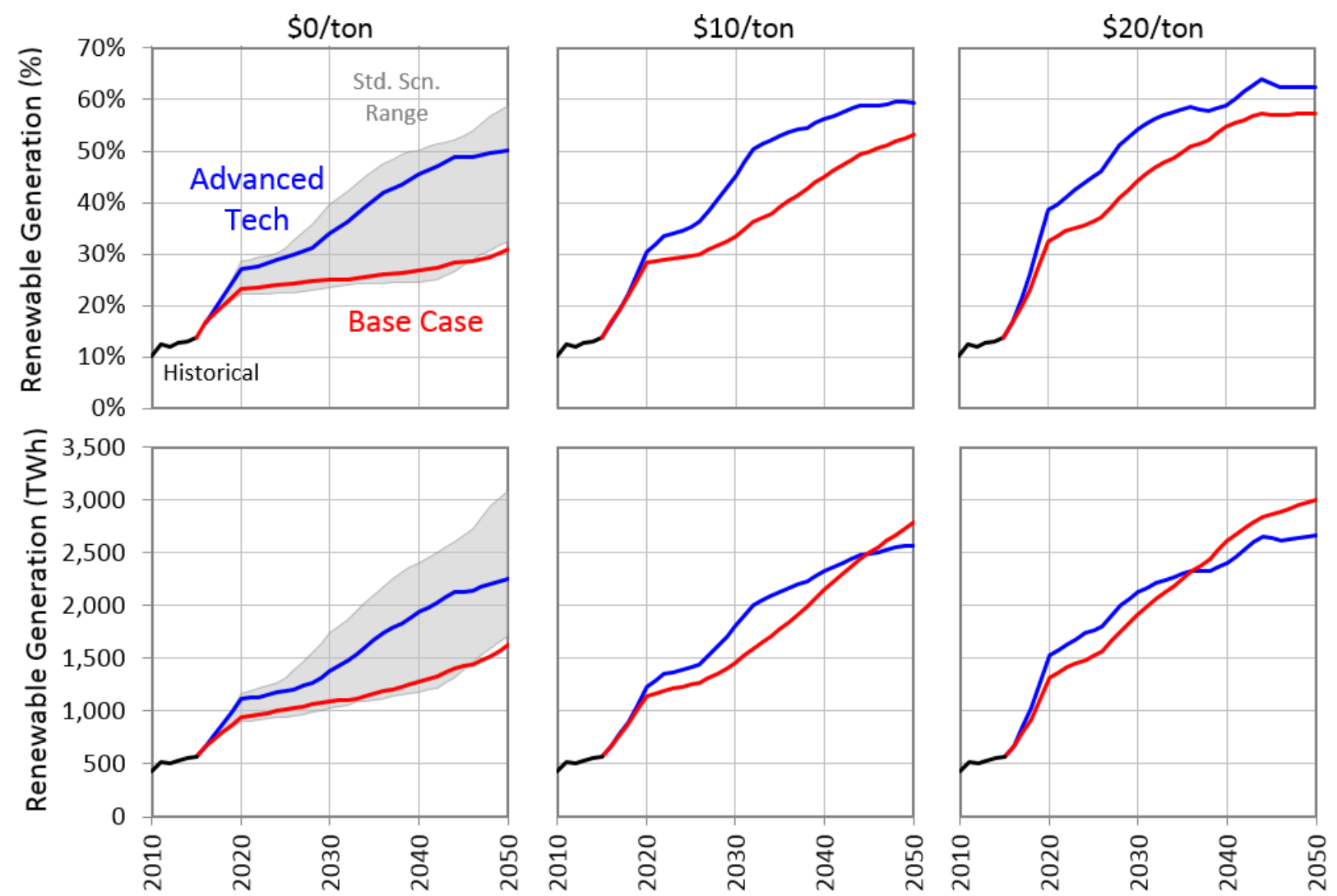

Figure ES-1. Modeled power sector renewable generation (bottom) and percent generation (top) under Base Case (red) and Advanced Technology Case (blue) scenarios, with \$0/ton (left), \$10/ton (middle), and \$20/ton (right) initial $\mathrm{CO}_{2}$ prices

The range of renewable generation associated with the scenarios in the 2016 Standard Scenarios report that explore a range of assumed future technology costs, fuel prices, and electricity demand is shown in grey. Historical generation from EIA is shown in black. 
2. Assumed improvements in nuclear and carbon capture utilization and sequestration (CCUS) technologies are insufficient to spur significant deployment without further market signals such as carbon emissions policies or higher than assumed costs for renewable technologies (Figure ES-2). In addition to renewable technologies, CCUS and nuclear technologies can provide low- or zero-carbon electricity generation. However, the achievement of all the technology targets represented in the Advanced Technology Case, without a price on $\mathrm{CO}_{2}$, yields no significant deployment of new capacity for these two technologies. The Advanced Technology Case technology improvements coupled with $\mathrm{CO}_{2}$ prices result in significant CCUS deployment in the power sector. Absent a $\mathrm{CO}_{2}$ price, CCUS remains more expensive than corresponding alternatives without CCUS. Similar amounts of nuclear generation were found in all technology improvement and $\mathrm{CO}_{2}$ price scenarios - no new nuclear capacity was added in any of the scenarios, indicating that new capacity for some other technologies were lower cost than new nuclear based on our assumptions and modeling.
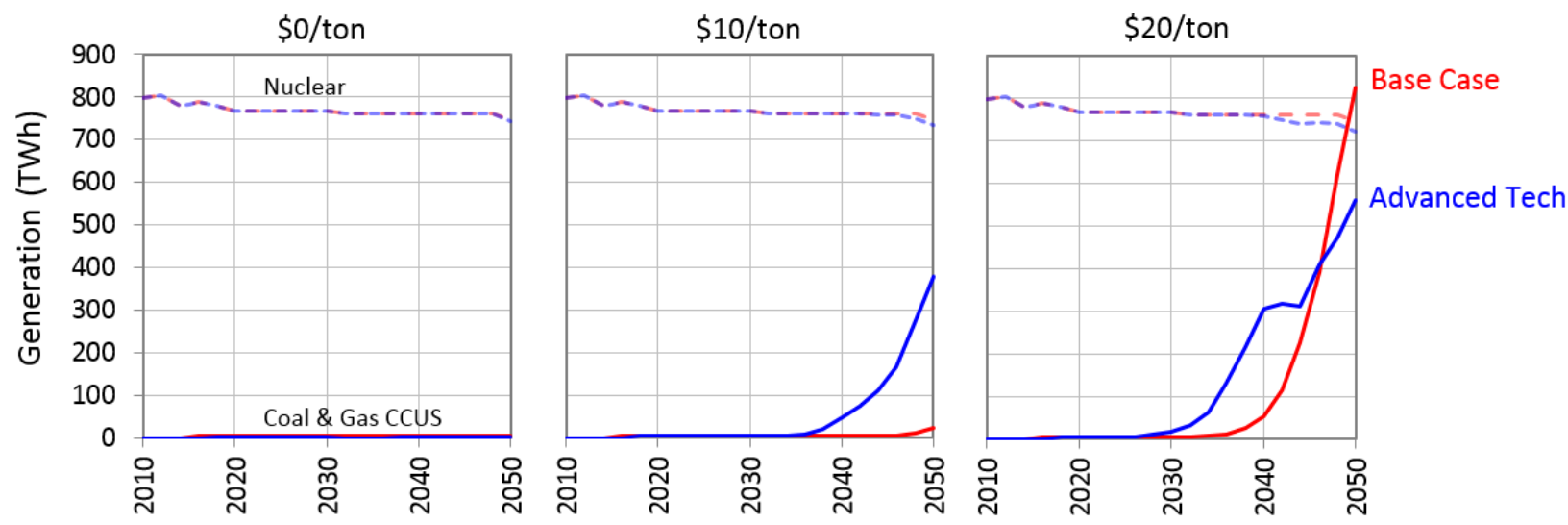

Figure ES-2. Modeled power sector nuclear (top, dashed) and coal and gas CCUS (bottom, solid) generation Base Case (red) and Advanced Technology Case (blue) scenarios, with \$0/ton (left), $\$ 10 /$ ton (middle), and $\$ 20 /$ ton (right) initial carbon prices

The vast majority of new CCUS is from natural gas CCUS generation. 
3. Natural gas-fired generation remains a significant portion of U.S. generation under all scenarios assuming gas prices stay low (Figure ES-3). Assuming natural gas prices remain low relative to historical prices (in the range of \$4 \$5/MCF real delivered power sector prices through 2050), generation from natural gas-fired technologies maintains a significant share of generation in all explored scenarios, even though no cost improvement is assumed for these technologies. Generation from natural gas without CCUS declines for both the Base Case and Advanced Technology Case scenarios coupled with carbon prices, but natural gas CCUS generation increases to keep total natural gas-sourced generation roughly constant after 2030. Absent a carbon price or successful RDD\&D in clean generation technologies, natural gas generation is projected to grow consistently through 2050 under the fuel price assumptions used. In all scenarios, natural gas capacity provides a range of grid services independent of projected trends in natural gas generation.
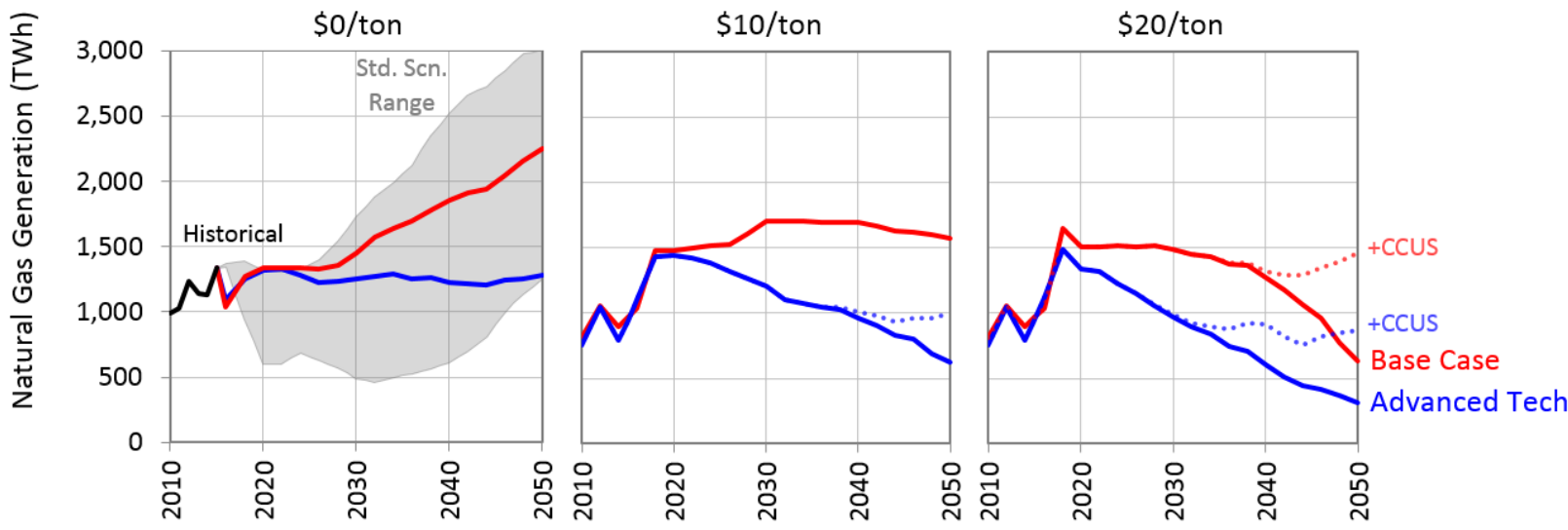

Figure ES-3. Modeled power sector natural gas generation under the Base Case (red) and Advanced Technology Case (blue) scenarios, with \$0/ton (left), \$10/ton (middle), and \$20/ton (right) initial carbon prices

Dotted lines add natural gas CCUS generation. The range of natural gas generation associated with the scenarios in the 2016 Standard Scenarios report that explore a range of assumed future technology costs, fuel prices, and electricity demand is shown in gray. 


\section{Lower direct power system expenditures could result from the achievement of the}

clean energy technology targets (Figure ES-4). The improved cost and performance of clean energy technologies assumed under the Advanced Technology Case lowers estimated direct power system expenditures by approximately $\$ 393$ billion (11\%) in net present value terms (2014\$), compared to the Base Case. These savings arise in part from reduced non-renewable fuel expenditures due to increased low-cost renewable generation and reduced electricity demand due to energy efficiency technology developments. These savings pertain only to direct expenditures within the electricity sector, including fuel, other operating, and capital costs for generation, transmission, and storage; the direct system costs presented in Figure ES-4 do not consider other factors that do not directly relate to expenditures within the electricity system, such as energy subsidies, RDD\&D activities, and environmental impacts. When taking into account estimates of additional costs from wind and solar tax credits and energy efficiency programs, savings are reduced to $\$ 309$ billion.

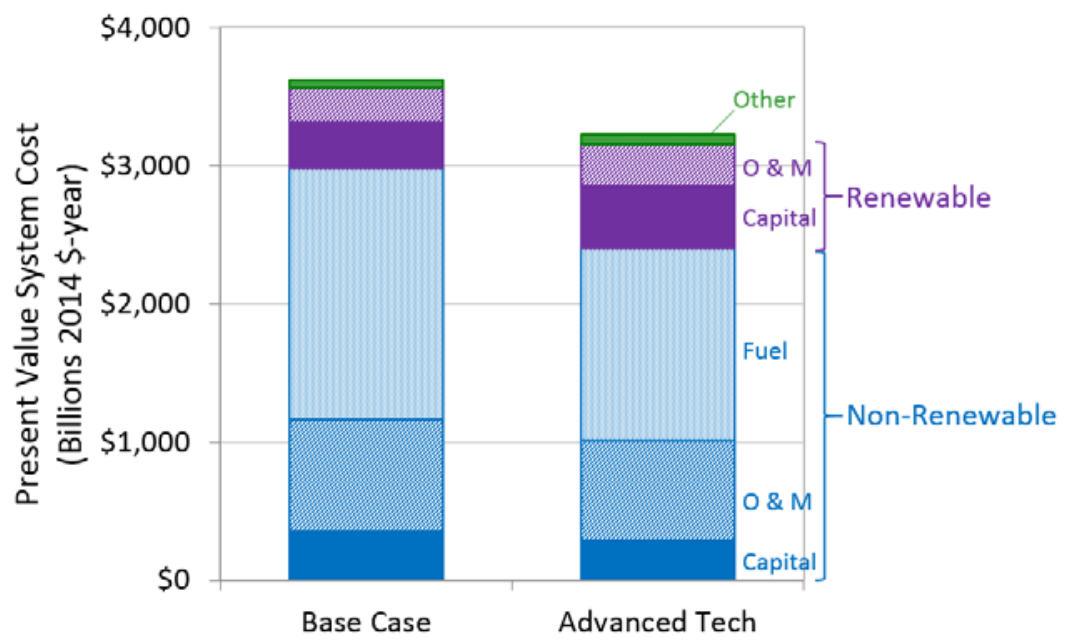

Figure ES-4. Present value of direct system expenditures from 2015 through 2050 with 3\% discount rate, in the Base Case and Advanced Technology Case scenarios, with no carbon price

The "Other" category includes transmission, storage, and water system costs. 
5. Power sector $\mathrm{CO}_{2}$ emissions would be substantially reduced as a consequence of increased generation from clean energy technologies and improved electricity enduse efficiency. Achievement of the assumed Advanced Technology Case cost and performance targets results in significant power sector carbon reductions; $\mathrm{CO}_{2}$ emissions in the Advanced Technology Case reach 72\% below 2005 levels by 2050, compared to $40 \%$ in the Base Case. The Advanced Technology Case shows similar emissions reductions to the scenario that coupled an initial $\$ 10 /$ ton $\mathrm{CO}_{2}$ price with Base Case technology cost assumptions. Assumed Advanced Technology Case technology improvements coupled with $\mathrm{CO}_{2}$ prices can achieve $80 \%$ or more power sector emissions reductions by 2050, relative to 2005 levels. Except for the Base Case without a $\mathrm{CO}_{2}$ price, all cases achieve emissions below the level called for in the Clean Power Plan.
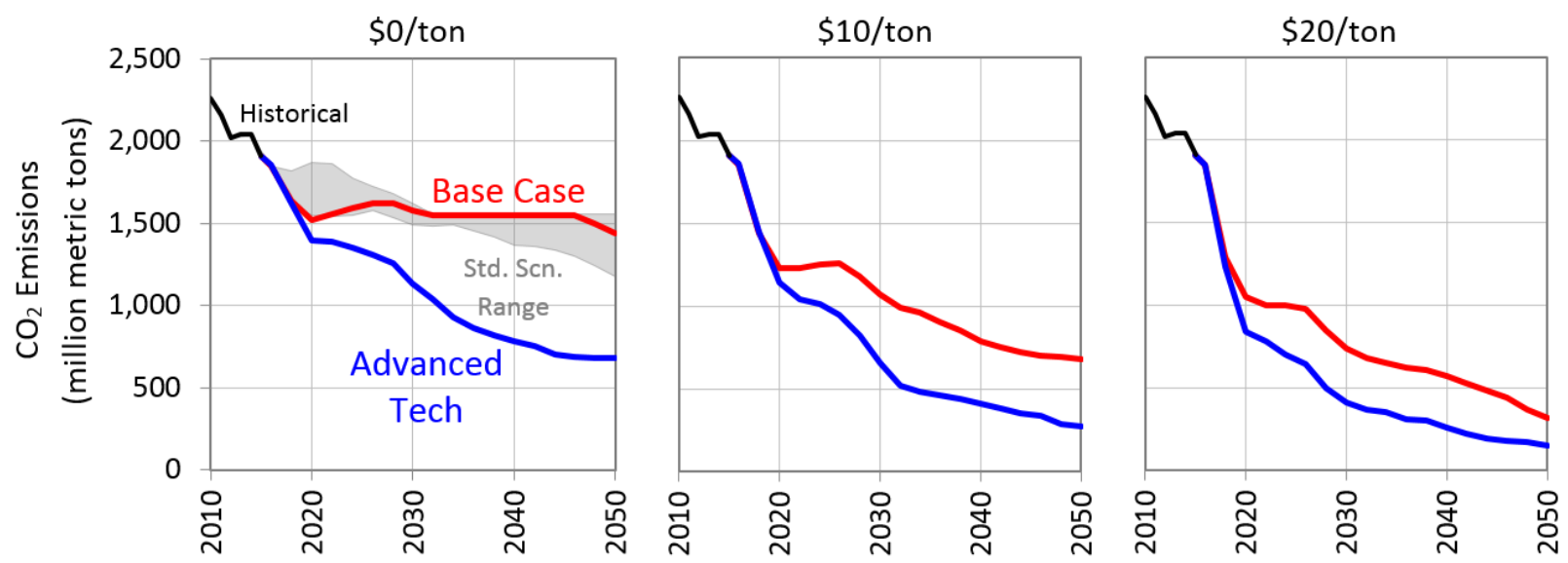

Figure ES-5. Modeled power sector $\mathrm{CO}_{2}$ emissions under Base Case (red) and Advanced Technology Case (blue) scenarios, with \$0/ton (left), \$10/ton (middle), and \$20/ton (right) initial carbon prices.

The range of emissions associated with the scenarios in the 2016 Standard Scenarios report that explore a range of assumed future technology costs, fuel prices, and electricity demand is shown in gray. 
While the above findings are largely qualitatively consistent with the power sector findings in the DOE (2017) study, including significant growth in clean generation, there are some differences to note. Our analysis shows approximately $650 \mathrm{TWh}$ more total renewable generation in 2040 in the Advanced Technology Case with no carbon price than seen in DOE (2017) for the same case. This difference is due to lower assumed costs for wind technologies in our case, along with differences in the models' representation of high levels of variable renewable generation. The lower-cost wind assumption also results in lower (no) new nuclear generation by 2040 than seen in DOE (2017), as well as significantly lower $\mathrm{CO}_{2}$ emissions in both our $\mathrm{CO}_{2}$ price scenarios coupled with Advanced Technology Case technology improvement assumptions.

As with the analysis from DOE (2017), our scenarios were designed to project the impacts related to specific sets of input assumptions and these projections are not intended as forecasts. In particular, it is important to note that this analysis considers only one representation of possible future generation technology costs and performance based on RDD\&D activities. Certain potential breakthroughs in technologies are not considered (e.g., small modular nuclear reactors, marine hydro kinetic) and individual technology improvements are not modeled in isolation. Consideration of either of these factors would likely result in different generation mixes. Accordingly, this analysis does not imply any RDD\&D activity prioritization or consider the likelihood of achievement of the technology-specific cost and performance targets assumed. The analysis also does not attempt to estimate the amount of RDD\&D investment needed to achieve the assumed technology cost reductions

Despite these limitations, the scenario results show that, assuming technology targets are achieved, clean generation technologies could provide a majority of U.S. electricity needs by 2050 and contribute to lower power system costs and power system $\mathrm{CO}_{2}$ emissions reductions. 


\section{Table of Contents}

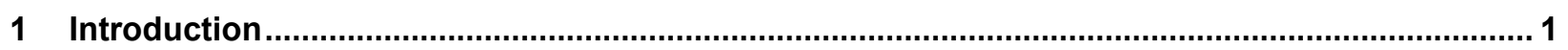

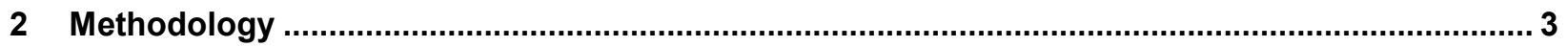

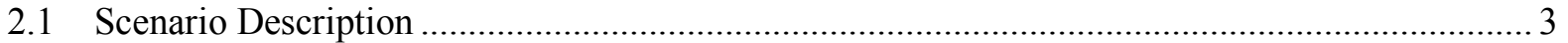

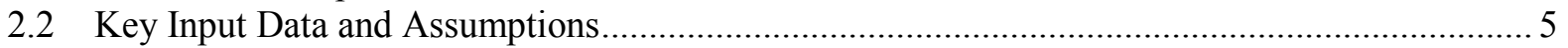

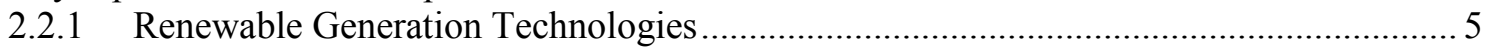

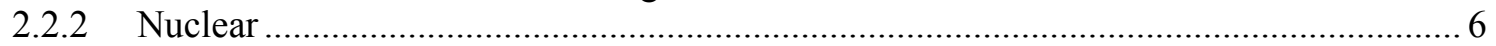

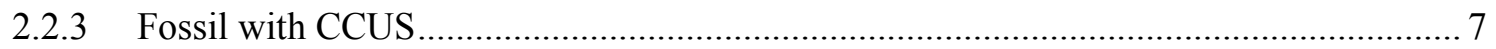

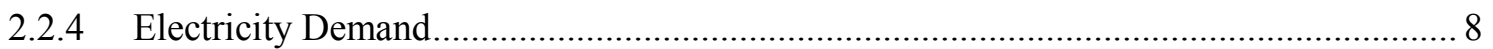

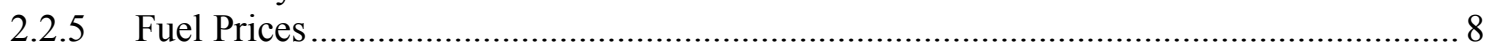

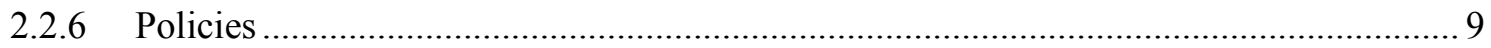

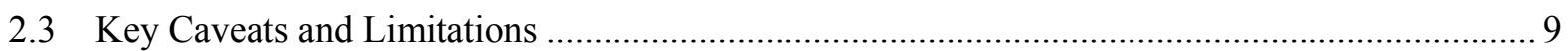

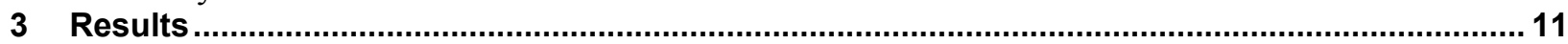

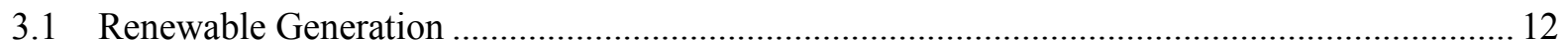

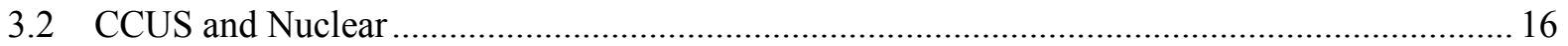

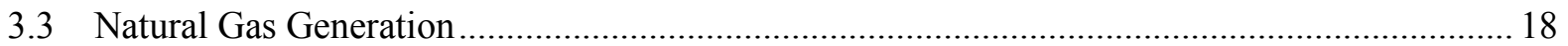

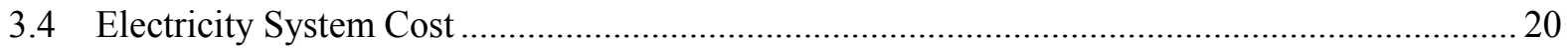

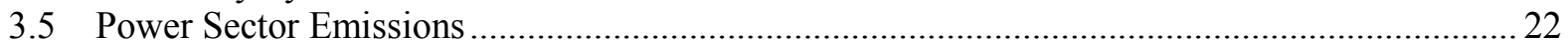

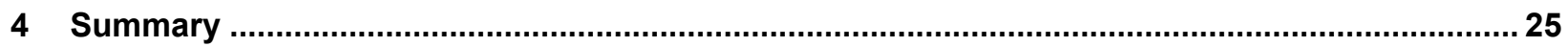

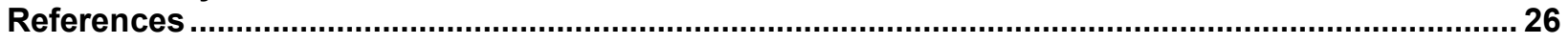

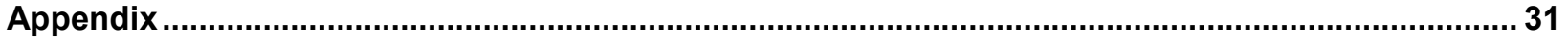

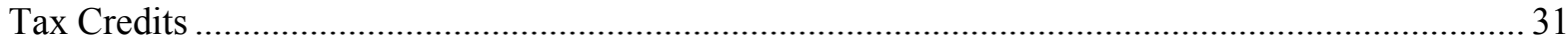

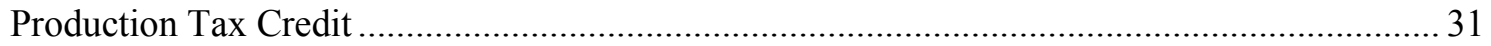

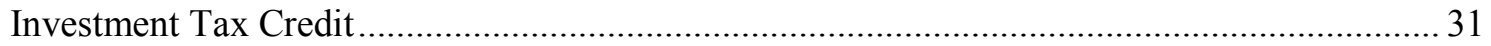

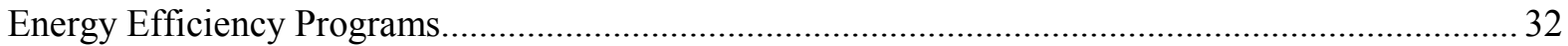

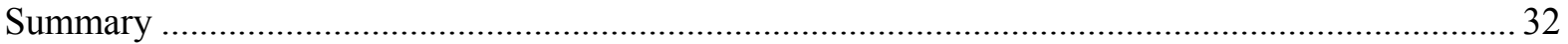




\section{List of Figures}

Figure ES-1. Modeled power sector renewable generation (top) and percent generation (bottom) under Base Case (red) and Advanced Technology (blue) scenarios, with \$0/ton (left), \$10/ton (middle), and $\$ 20 /$ ton (right) initial CO2 prices

Figure ES-2. Modeled power sector nuclear (top, dashed) and coal and gas CCUS (bottom, solid) generation Base Case (red) and Advanced Technology (blue) cases, with \$0/ton (left), \$10/ton (middle), and $\$ 20 /$ ton (right) initial carbon prices

Figure ES-3. Modeled power sector natural gas generation under the Base Case (red) and Advanced Technology (blue) scenarios, under \$0/ton (left), \$10/ton (middle), and \$20/ton (right) initial carbon prices

Figure ES-4. Present value of total system costs output from ReEDS from 2015 through 2050 with 3\% discount rate, in the Base Case and Advanced Technology Cases with no carbon price

Figure ES-5. Modeled power sector $\mathrm{CO}_{2}$ emissions under Base Case (red) and Advanced Technology (blue) scenarios, along with initial $\mathrm{CO}_{2}$ emissions prices of $\$ 0$ (left), $\$ 10$ (center), and $\$ 20$ (right) per metric ton

Figure 1. Historical power sector electricity generation by fuel type.

Figure 2. Levelized cost of electricity for new fossil and nuclear (left), utility-scale PV (middle) and landbased wind (right) electricity generating technologies, in the Base (solid) and Advanced Technology (dotted) cases, with no $\mathrm{CO} 2$ price and without tax credits

Figure 3. Generation by technology category under Base Case (top row) and Advanced Technology (bottom row) scenarios, under \$0/ton (left), \$10 (center), and \$20/ton (right) initial carbon prices, showing renewables (green), nuclear (red), CCUS (purple), natural gas (gray), and coal (black) generation sources

Figure 4. Difference in generation between the Advanced Technology Case and the Base Case by technology category, under $\$ 0 /$ ton (left), $\$ 10$ (center), and $\$ 20 /$ ton (right) initial carbon prices, showing renewables (green), nuclear (red), CCUS (purple), natural gas (gray), and coal (black) generation sources

Figure 5. Modeled power sector renewable generation (top) and generation share (bottom) under Base Case (red) and Advanced Technology Case (blue) scenarios, with \$0/ton (left), \$10/ton (middle), and $\$ 20 /$ ton (right) initial $\mathrm{CO}_{2}$ prices

Figure 6. Modeled power sector nuclear (top, dashed) and coal and gas CCUS (bottom, solid) generation Base Case (red) and Advanced Technology Case (blue) generation cost and performance assumptions, with $\$ 0 /$ ton (left), \$10/ton (middle), and $\$ 20 /$ ton (right) initial $\mathrm{CO}_{2}$ prices

Figure 7. Modeled power sector natural gas generation for the Base Case (red) and Advanced Technology Case (blue) scenarios, under \$0/ton (left), \$10/ton (middle), and \$20/ton (right) initial carbon prices. Dotted lines add natural gas CCUS generation.

Figure 8. Present value of total system costs output from ReEDS from 2015 through 2050, discounted at $3 \%$, in the Base Case and the Advanced Technology Case.

Figure 9. Modeled power sector $\mathrm{CO}_{2}$ emissions under Base Case (red) and Advanced Technology Case (blue) scenarios, along with initial $\mathrm{CO}_{2}$ emissions prices of $\$ 0$ (left), $\$ 10$ (center), and $\$ 20$ (right) per metric ton 


\section{List of Tables}

Table 1. Summary of New Renewable Generation LCOE for the Advanced Technology Case in 2050, and the LCOE reduction in 2050 Relative to the Base Case

Table 2. Projected 2050 Power Sector CO2 Emissions Reductions relative to 2005 24

Table A-1. Upper Bound Estimates of Present Value for Additional Costs in the Advanced Technology Case Relative to the Base Case, 2015-2050 (billions, 2014 dollars)..... 


\section{Introduction}

The U.S. power sector has undergone significant changes in recent years, as seen in Figure 1. Substantial growth in natural gas generation has occurred over the most-recent decade, along with growth in wind and solar renewables and a sharp decline in coal generation. After decades of continual growth, electricity sales have grown more slowly over the last decade. Electricity sales have grown at a compound annual rate of $0.27 \%$ since 2006 compared with annual growth rates typically in the range of 1\%-8\% from 1960 to 2005 (EIA 2016j). The combination of these trends has led to decreasing carbon dioxide $\left(\mathrm{CO}_{2}\right)$ emissions from the power sector to levels not observed since 1993 (EIA 2016g).

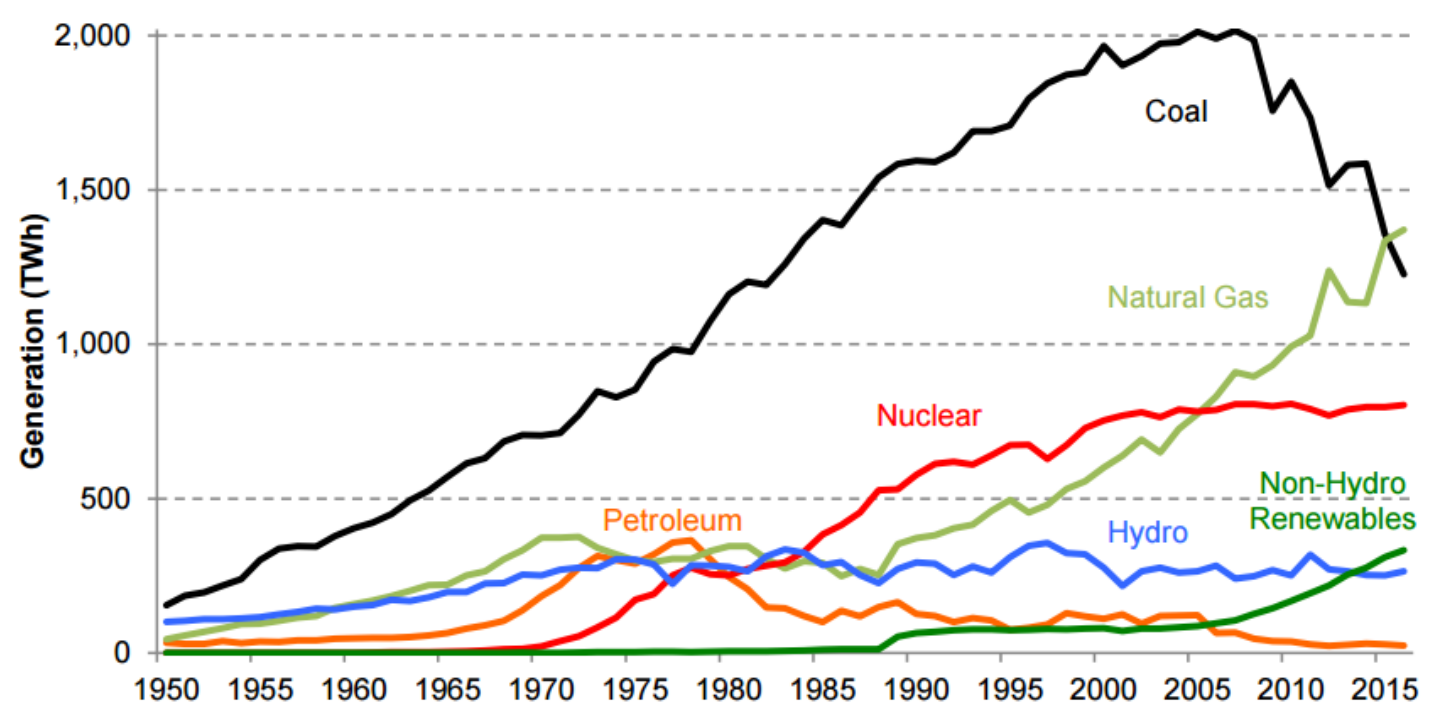

Figure 1. Historical power sector electricity generation by fuel type

Values for 2016 are based on a 12-month rolling total through April 2016. Data from EIA (2016j), figure from Cole, Mai et al. (2016).

These trends have been driven by reductions in the cost and performance of specific generation technologies, supporting policies, and market factors. Many of these recent changes in the power sector have been enabled by previous investments in research, development, demonstration, and deployment (RDD\&D) activities funded by the U.S. federal government, some state governments, other countries, private sector corporations, and other non-governmental organizations. An example of successful RDD\&D includes hydraulic fracturing and horizontal drilling technologies and techniques for shale oil and gas resource extraction, which were enabled by innovation investments by the oil and gas industry as well as by support from the U.S. Department of Energy (DOE) Office of Fossil Energy (DOE 2016c; MIT 2011). Historical RDD\&D activities in DOE's wind and solar technology programs have also contributed to the growth observed in these technologies over the last decade (DOE 2010a DOE 2010b).

With this context, questions arise as to how further technology improvements enabled by current and future RDD\&D activities could further impact the U.S. power sector. Key questions include:

- How could the future generation mix change if clean energy technologies in the power sector achieve lowered cost and improved performance enabled by RDD\&D investment? 
- How do these potential changes in generation compare to the range of outcomes projected based on other sensitivities previously explored?

- How might clean energy technology deployment, enabled by RDD\&D activities, help to lower future electric system costs?

- How do these potential RDD\&D-driven changes in generation compare and synergize with the impacts of potential carbon emissions policies?

As explained further in Section 2, we use the DOE Technology Offices' technology $\operatorname{targets}^{4}$ as proxies for what improved technology cost and performance could be achieved through RDD\&D investment. The targets are developed independently by each Office using various methodologies, and reflect ambitious but feasible levels of technology improvement. As implemented in this analysis, these targets represent improvements in clean energy technologies in all energy sectors, from electricity generation to end-use technologies, along with changes to consumer behavior embedded in electricity demand assumptions. We recognize that it is challenging to predict specific advancements in technologies: some technology improvements here may not be achieved; conversely, other unforeseen progress and breakthroughs not captured in this set of assumptions may occur.

The suite of technology improvements embedded in these input assumptions represents just one possible outcome from RDD\&D activities. However, we also compare the results to those published in the NREL 2016 Standard Scenarios (Cole, Mai et al. 2016), which explored the impact of a range of sensitivities in natural gas prices, electricity demand, and capacity retirement, among others. By comparing the impacts of RDD\&D-enabled technology improvements to the range of results in the NREL 2016 Standard Scenarios we can determine the magnitude of the impact of improvement in technology cost and performance compared to these other factors.

In addition to the technology improvements, we also compare the impact of RDD\&D-enabled technology improvements both in conjunction with and separate from the impact of hypothetical additional policies to reduce greenhouse gas emissions, in the form of $\mathrm{CO}_{2}$ emissions prices. Similar to the impact of improved technology cost and performance, these types of policies provide a driver to increased deployment of clean electricity generating technologies. This comparison also allows us to examine the impacts of clean energy RDD\&D relative to the magnitude of impacts achieved with policy alone and how the impacts of RDD\&D work with potential policies.

Our analysis builds on a recently completed study, "Energy $\mathrm{CO}_{2}$ Emissions Impacts of Clean Energy Technology Innovation and Policy," by the DOE's Office of Energy Policy and Systems Analysis (EPSA), which relied on a version of the National Energy Modeling System (NEMS) economy-wide model (DOE 2017). As described in Section 2, we leverage this work, hereinafter referred to as the EPSA-NEMS analysis, by relying on its outputs to serve as inputs for our modeling. Although our and the EPSA-NEMS analyses are related, they differ in three important aspects. First, our focus is solely on the U.S. power sector, whereas the EPSA-NEMS analysis explores a broader set of clean energy technologies and energy sector impacts. Second, we apply

\footnotetext{
${ }^{4}$ These include inputs from the Office of Energy Efficiency and Renewable Energy, Office of Fossil Energy, Office of Nuclear Energy, Office of Electricity Delivery and Energy Reliability.
} 
a higher-resolution model of the electricity system that is designed specifically to explore issues related to clean electricity generation, particularly renewable energy. Finally, our analysis includes an assessment of relative power sector system costs between scenarios. Nonetheless, the two analyses are complementary and have largely consistent high-level findings. ${ }^{5}$ Relevant comparisons for results between this analysis and the EPSA-NEMS results are presented in Section 3.

We first outline the details and methods that were used to develop the inputs and assumptions for the different cases below, along with key caveats that should be considered when interpreting results. We then explore the results regarding trends in specific categories of electricity generating technologies, before assessing the impacts on overall system costs and power sector $\mathrm{CO}_{2}$ emissions.

\section{Methodology}

This analysis was performed primarily with the Regional Energy Deployment System (ReEDS) U.S. electricity sector capacity expansion model, a high spatial resolution model that identifies the least-cost portfolio of generation and other electric system infrastructure needed to meet future electricity demands and policy needs. ReEDS is documented in detail in Eurek et al. (2016) and used in the NREL 2016 Standard Scenarios report (Cole, Mai et al. 2016). Distributed photovoltaic generation is modeled separately using the NREL Distributed Generation model, documented in Sigrin et al. (2016).

\subsection{Scenario Description}

There are two main scenarios developed for this analysis, the Base Case and the Advanced Technology Case. The Base Case is a reference scenario representing business-as-usual conditions for fuel prices, electricity demand, along with moderate improvements in cost and performance of new generation technologies resulting from moderate success in RDD\&D. With the few exceptions described below, the Base Case relies on the same assumptions as the MidCase scenario from the 2016 Standard Scenarios report. To estimate the impact of achieving RDD\&D targets, the Advanced Technology Case uses inputs that assume further cost and performance improvement to clean electricity technologies and additional adoption of clean energy end-use technologies over time. Note that the Advanced Technology Case assumes improvements in all modeled clean generation technologies at the levels described below.

The DOE Technology Offices develop individual technology cost and performance goals as a regular part of the budgetary process, as described in more detail in the EPSA-NEMS analysis (DOE 2017). These performance goals typically take the form of specific cost targets, such as the DOE SunShot target of utility-scale photovoltaic power at $\$ 0.06 / \mathrm{kWh}$ by 2020 (DOE 2016d). These targets are developed through technical analyses by DOE Technology Offices, often along with potential specific technology advancements that could achieve these targets (for example, see Woodhouse et al. 2016). While the goals are developed independently by each office and reflect differences in methodology, together they represent a portfolio of a possible scenario

\footnotetext{
${ }^{5}$ A key finding from the EPSA-NEMS analysis is that "successful RDD\&D activities that drive advancement of clean energy technologies, supported by deployment activities that reduce or eliminate specific market barriers, can result in significant reductions in energy $\mathrm{CO} 2$ emissions."
} 
outcome of RDD\&D activities. This process and method could result in differing levels of optimism or likelihood across the technology projections.

Modeling inputs from the EPSA-NEMS analysis were derived from goals developed for DOE's FY17 budget, through consultation with DOE Technology Office staff (DOE 2017). For the Advanced Technology Case, we rely on the same input technology cost and performance assumptions for nuclear and carbon capture utilization and sequestration (CCUS) technologies developed for the EPSA-NEMS analysis. Our analysis also uses outputs of the EPSA-NEMS analysis for the Advanced Technology Case for areas that ReEDS does not explicitly model; more specifically, for the Advanced Technology Case scenarios, we rely on the electricity demand growth outputs, which take into account energy efficiency adoption and electrification, and fossil fuel price outcomes, which consider fossil resources and consumption in the full economy. Note that our Base Case assumptions differ from the reference case assumptions in the EPSA-NEMS analysis and some other differences exist in the Advanced Technology Case as well as noted below.

Figure 2 presents a comparison of the impact of Advanced Technology Case inputs on the levelized cost of electricity (LCOE) for electricity generating technologies that are most relevant to our analysis. Although LCOEs are shown in Figure 2 and Table 1 to characterize the level of cost reductions envisioned in the two assumed technology projections, the LCOE metric does not fully reflect the competitiveness of different technologies as it does not consider all impacts to the electricity system nor does it consider relative value between technologies. ReEDS considers a more-complete set of system impacts, particularly for renewable technologies, in its decision making (Eurek et al. 2016). For example, LCOEs for wind and solar displayed in Figure 2 and Table 1 do not include grid interconnection costs or other integration factors. For fossil and nuclear technologies, the LCOE calculations assume $90 \%$ capacity factor and average fuel prices based on the outcome from the corresponding ReEDS scenarios. We use the default financing assumptions in ReEDS to estimate LCOEs for all technologies.
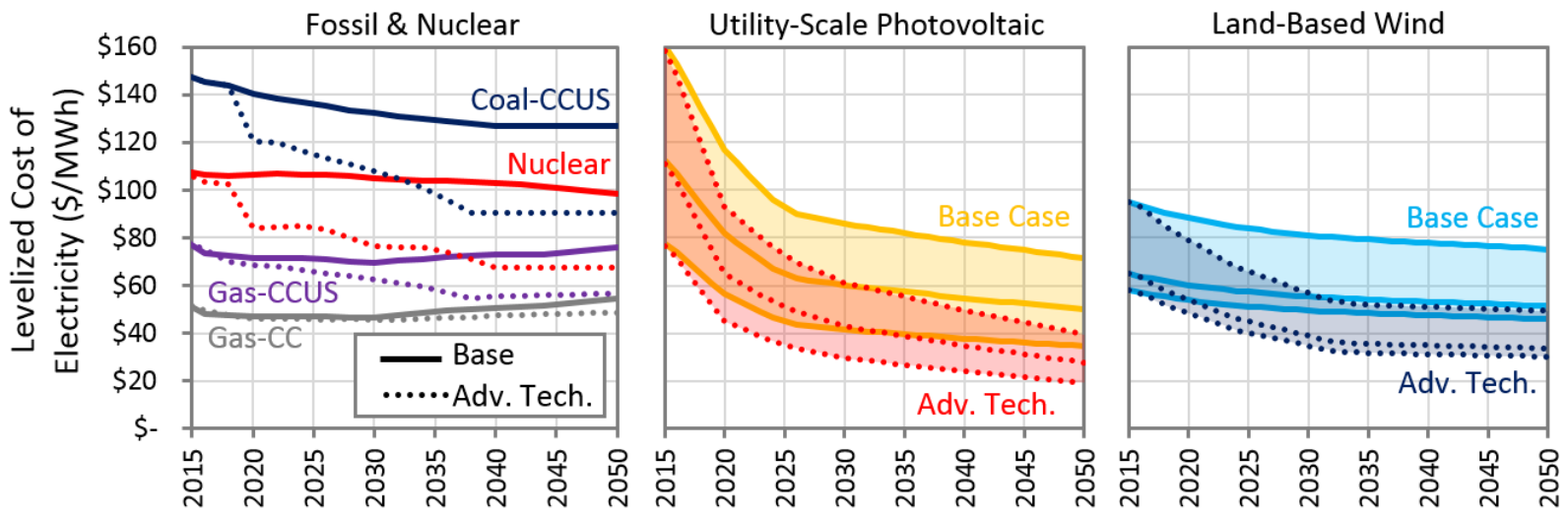

Figure 2. Levelized cost of electricity for new fossil and nuclear (left), utility-scale PV (middle) and land-based wind (right) electricity generating technologies, in the Base (solid) and Advanced Technology (dotted) cases, with no $\mathrm{CO} 2$ price and without tax credits

Ranges for wind and PV represent the spread in resource potential. Utility-scale PV shows capacity factors of $29 \%$ (bottom), 20\% (middle), and 14\% (top), and wind shows techno-resource group (TRG) 1 (bottom), TRG 4 (middle), and TRG 7 (top). 
In addition to the main Base Case and Advanced Technology Case inputs, a set of $\mathrm{CO}_{2}$ price scenarios are layered on top of the technology scenarios to examine the impact of technology advancement in comparison to and in combination with carbon policy. In addition to a no- $\mathrm{CO}_{2}$ price scenario, we model scenarios with $\$ 10 /$ ton and $\$ 20 /$ ton $^{6}$ initial $\mathrm{CO}_{2}$ prices starting in 2017 and rising at $5 \%$ annual in real terms. ${ }^{7}$ This creates a set of six different scenarios: Base Case and Advanced Technology Case inputs with $\$ 0 /$ ton, $\$ 10 /$ ton, and $\$ 20 /$ ton initial $\mathrm{CO}_{2}$ prices. The key inputs and assumptions for these scenarios are described next.

\subsection{Key Input Data and Assumptions}

\subsubsection{Renewable Generation Technologies}

The renewable generation technologies included in this analysis include utility-scale and distributed solar photovoltaic (PV), concentrating solar power (CSP), land-based and off-shore wind power, hydropower, geothermal, and co-fired and dedicated biopower. ${ }^{8}$ For the most part, this collection of technologies is currently commercially available; we exclude newer renewable technologies, such as marine hydrokinetic, which have not yet achieved commercial deployment but could see deployment by 2050 .

The Base Case future cost and performance improvement assumptions for renewable technologies are based on the NREL 2016 Annual Technology Baseline (ATB) Mid-case cost projection (NREL 2016). The Base Case, with these underlying assumptions, serves as a reference point for which to compare the impacts of lower technology costs. Most notably, the Base Case cost for new renewable generation does decline moderately, reflecting some amount of continued RDD\&D activities.

In general, the Advanced Technology Case uses the NREL 2016 ATB Low-Case cost projection as a proxy for DOE program goals for renewable generation technologies, with some notable exceptions. For example, while the ATB Low-Case cost projection for utility-scale PV nearly achieves the 2020 SunShot goal of $\$ 0.06 / \mathrm{kWh}$, it does not achieve the recently announced 2030 SunShot goals for solar power (DOE 2016e) and the impact of the 2030 goal is not included in this analysis. ${ }^{9}$ Additionally, the ATB Low-Case projection does not reach goals for both landbased and off-shore wind technologies, so we use a trajectory developed to explicitly represent the DOE Wind Energy Technologies Office goals.

As noted in Section 3, the majority of the new renewable deployment is from PV and land-based wind generation. Figure 2 shows the comparison of LCOE between the Base Case and Advanced Technology Case trajectories for these two technologies. The LCOE ranges reflect regionallyvarying differences of renewable resource quality as captured in ReEDS, and as further described in NREL 2016. Utility-scale PV LCOE declines to \$19/MWh-\$40/MWh in 2050 in the

\footnotetext{
${ }^{6}$ All use of "tons" in this report refers to metric tons.

${ }^{7}$ Under this escalation, the initial \$10/ton and \$20/ton prices reach \$50/ton and \$100/ton, respectively, by 2050.

${ }^{8} \mathrm{We}$ do not vary biomass generation costs between scenarios and rely on assumptions from the Annual Technology Baseline Mid-case cost assumptions for co-firing and biopower costs in all scenarios. Generation from biomass is included in reported aggregate renewable generation totals. DOE goals for biomass generation do not currently exist. Resource and technology assumptions for CSP, geothermal, and hydropower are as modeled in the NREL 2016 Standard Scenarios (Cole, Mai et al. 2016).

${ }^{9}$ This analysis was completed before the 2030 SunShot goals (DOE 2016e) were announced and therefore did not include these newer goals from the DOE Solar Energy Technologies Office.
} 
Advanced Technology Case, which is $45 \%$ lower than the Base Case LCOE. Land-based wind LCOE declines to \$30-\$49/MWh in 2050 in the Advanced Technology Case, which is 34\% lower than the Base Case LCOE. Table 1 summarizes the assumed renewable 2050 LCOE ranges in the Advanced Technology Case shows how they compare with LCOEs from the Base Case.

Table 1. Summary of New Renewable Generation LCOE for the Advanced Technology Case in 2050, and Comparisons with the Base Case

\begin{tabular}{|c|c|c|c|}
\hline Technology & $\begin{array}{l}2050 \text { LCOE in } \\
\text { Advanced Technology } \\
\text { Case (2014-\$/MWh) }\end{array}$ & $\begin{array}{l}\text { \% Reduction } \\
\text { Compared to } \\
\text { Base Case }\end{array}$ & Notes \\
\hline PV (Utility-Scale) & $\$ 19-\$ 40$ & $45 \%$ & \multirow{3}{*}{$\begin{array}{l}\text { ATB Low-Case projections do not } \\
\text { align with recently announced } \\
\text { DOE SunShot } 2030 \text { targets } \\
\text { (DOE 2016e) }\end{array}$} \\
\hline PV (Residential) & $\$ 55-\$ 92$ & $18 \%$ & \\
\hline PV (Commercial) & $\$ 52-\$ 86$ & $15 \%$ & \\
\hline CSP & $\$ 62-\$ 87$ & $21 \%$ & $\begin{array}{l}\text { Includes } 6-10 \text { hours of thermal } \\
\text { energy storage }\end{array}$ \\
\hline Wind (Land-Based) & $\$ 30-\$ 49$ & $34 \%$ & $\begin{array}{l}\text { Range shown here includes TRG } \\
1-7 . \text { TRG } 8-10 \text { also modeled. }\end{array}$ \\
\hline Wind (Off-Shore) & $\$ 81-\$ 113$ & $23 \%$ & $\begin{array}{l}\text { Includes fixed bottom and floating } \\
\text { technologies }\end{array}$ \\
\hline Geothermal & $\$ 68-\$ 193$ & $14 \%$ & $\begin{array}{l}\text { Includes hydrothermal and near- } \\
\text { field enhanced geothermal } \\
\text { systems }\end{array}$ \\
\hline Hydropower & $\$ 62-\$ 112$ & $25 \%-34 \%$ & $\begin{array}{l}\text { Includes upgrades, non-powered } \\
\text { dams, and new stream } \\
\text { development }\end{array}$ \\
\hline
\end{tabular}

\subsubsection{Nuclear}

In all scenarios, we assume that existing nuclear facilities have 80-year lifetimes through no nocost license extensions. ${ }^{10}$ Announced nuclear retirements are reflected in the same fashion as the Mid-Case scenario from the 2016 Standard Scenarios and do not reflect all of the most-recent announcements. ${ }^{11}$ ReEDS also does not capture endogenous economic retirements nor does it ensure revenue sufficiency for individual plants, meaning that there could be increased nuclear retirements in existing facilities than what is projected due to competition from other generation sources. In addition, neither scenario explicitly models the potential impact of small modular reactors that may become commercially available by 2050 .

The Base Case uses nuclear cost and performance assumptions from the 2016 ATB Mid-Case. ${ }^{12}$ For this case, nuclear overnight capital costs are assumed to be about $\$ 5,500 / \mathrm{kW}$ in 2015 and to

${ }^{10}$ This assumption differs from the 60-year nuclear lifetime assumption used in the majority of the 2016 Standard Scenarios. No facilities have been granted an operating license extension to 80 years.

${ }^{11}$ Announced retirements were based on the ABB Velocity Suite database from April 1, 2016 (see Cole, Mai et al. 2016).

${ }^{12}$ For non-renewable technologies including nuclear and fossil (with and without CCUS) technologies, the ATB 2016 assumptions are based on cost and performance assumptions from the EIA's Annual Energy Outlook 2016 Reference Case. 
reduce by $5 \%$ by 2030 and $15 \%$ by $2050 .{ }^{13}$ The Advanced Technology Case assumes a $23 \%$ reduction (from 2015) in overnight capital costs by $2022,34 \%$ by 2030 , and $47 \%$ by $2050 .{ }^{14}$ For the Advanced Technology Case, we also assume 9\% lower fixed operations and maintenance (O\&M costs) compared with the Base Case and no variable O\&M costs. These assumptions together result in a LCOE of \$68/MWh by 2050 in the Advanced Technology Case, 31\% lower than the Base Case (Figure 1).

\subsubsection{Fossil with CCUS}

As with renewable and nuclear technologies, Base Case assumptions rely on the 2016 ATB MidCase for fossil generation with CCUS. Under these assumptions, overnight capital costs for new natural gas combined cycle with CCUS (NG-CCUS) capacity is assumed to be $\$ 2,100 / \mathrm{kW}$ in 2015 and to reduce by $12 \%$ by 2030 and $25 \%$ by 2050 . NG-CCUS heat rates in the Base Case are 7.5 MMBtu/MWh for all years. The Advanced Technology Case assumes a $16 \%$ reduction (relative to 2015) in capital costs by 2030 and $26 \%$ reduction by $2050 .{ }^{15}$ Heat rate improvements for NG-CCUS technology are also assumed in the Advanced Technology Case; heat rates are assumed to be $15 \%$ lower by 2030 and $31 \%$ lower by 2050 , relative to the Base Case. With no $\mathrm{CO}_{2}$ price, this results in an LCOE of $\$ 57 / \mathrm{MWh}$ by 2050 in the Advanced Technology Case, $25 \%$ lower than the Base Case (Figure 1).

Base Case assumptions for coal with CCUS include overnight capital costs of about $\$ 6,550 / \mathrm{kW}$ in 2015 , reducing $10 \%$ by 2030 and $16 \%$ by 2050 . Coal-CCUS-assumed heat rates in the Base Case are 9.9 MMBtu/MWh in 2015, reducing to 8.3 MMBtu/MWh by 2025, after which they are assumed to remain constant. The Advanced Technology Case assumes a $37 \%$ reduction from 2015 in capital costs by 2030 and $49 \%$ reduction by $2050 .{ }^{16}$ Coal-CCUS heat rate assumptions in the Advanced Technology case start out higher than the Base Case, but they are projected to be lower in the long run; heat rates for coal-CCUS are assumed to be $10 \mathrm{MMBtu} / \mathrm{MWh}$ in 2025, declining to $8.1 \mathrm{MMBtu} / \mathrm{MWh}$ by 2038, and staying at that level thereafter. With no $\mathrm{CO}_{2}$ price, this results in an LCOE of \$90/MWh by 2050 in the Advanced Technology Case, 29\% lower than the Base Case (Figure 1). The above data are for new coal-CCUS plants. ReEDS also models CCUS retrofits for existing coal-fired facilities but for the present analysis, such retrofits played a negligible role.

Both natural gas and coal with CCUS technologies in ReEDS are assumed to have a $90 \% \mathrm{CO}_{2}$ capture rate, which means LCOEs for CCUS technologies increase slightly with $\$ 10 /$ ton and $\$ 20 /$ ton initial $\mathrm{CO}_{2}$ prices. We do not model other CCUS technologies, for example, those with

\footnotetext{
${ }^{13}$ Except for plants that are already under construction, we assume new nuclear and CCUS plants can be installed only starting in 2022 to account for the permitting and construction periods required for these facilities. Cost and performance improvements are assumed between 2015 and 2022; improvements over this time period are assumed to be relatively modest in the Base Case but more-significant for the Advanced Technology Case.

${ }^{14}$ We assume that cost and performance assumptions are constant from 2040 to 2050 for nuclear and CCUS.

${ }^{15}$ Fixed and variable O\&M costs are assumed to be constant over time in the Base Case but in the Advanced Technology case are assumed to be lower by $6 \%$ and $14 \%$ (relative to the Base Case) by 2030 and 2050 , respectively.

${ }^{16}$ As with NG-CCUS, Coal-CCUS O\&M costs are assumed to be constant over time in the Base Case but decrease in the Advanced Technology Case. By 2050, fixed O\&M costs are 49\% lower in the Advanced Technology Case compared to the Base Case and variable O\&M costs are $42 \%$ higher.
} 
different capture rates, which could be used for minimum compliance with EPA New Source Performance Standards (EPA 2015a).

\subsubsection{Electricity Demand}

Although ReEDS has the capability to model the price elasticity of demand for electricity, it does not endogenously model adoption of energy efficiency. As such, for this analysis we rely on the AEO 2016 (EIA 2016a) and the EPSA-NEMS analysis (DOE 2017) to capture the effect of RDD\&D on electricity end-use technologies and electricity demand. More specifically, the Base Case annual electricity consumption assumptions arise from the AEO 2016 Reference case. We apply the same electricity demand assumptions for all $\mathrm{CO}_{2}$ price scenarios under Base Case assumptions.

We rely on electricity demand growth outputs from the EPSA-NEMS analysis for all Advanced Technology Cases, including separate demand assumptions for the different $\mathrm{CO}_{2}$ price scenarios. The Advanced Technology Case demand input includes assumptions that result in lowering of building energy consumption per square foot by 30\% in 2030 from 2010 levels, which is achieved through additional appliance standards, building codes, improvements in cost and performance of efficiency technologies, and increased consumer preference for efficiency technologies and upgrades (DOE 2017). The Advanced Technology Case demand assumptions also account for growing electricity demand due to increased deployment of electric vehicles related to meeting DOE cost and performance goals regarding electric-vehicle batteries. On net, however, the Advanced Technology Cases have lower electricity consumption than the Base Cases.

The impact of these improvements in end-use technologies on demand for electricity generation is significant. By 2050, electricity generation to meet demand in the Base Case grows $33 \%$ over 2016 demand to 4,996 TWh, compared to growing only $12 \%$ and reaching 4,261 TWh in the Advanced Technology Case without a $\mathrm{CO}_{2}$ price. The impact of $\mathrm{CO}_{2}$ prices are found, from the EPSA-NEMS analysis, to have a noticeable but more-limited impact on annual electricity consumption with 2050 electricity generation to meet demand reaching 4,043 TWh in the \$20/ton initial $\mathrm{CO}_{2}$ price Advanced Technology Case.

Note that some of the electricity price impacts on demand and end-user behavior are not fully reflected in these results. For example, if RDD\&D results in lower-cost electricity, then there may be reduced incentives for end-users to adopt energy efficient technologies, or increased incentives for end-users to switch from non-electric to electric technologies. While it is uncertain how much these dynamics would impact results, they are partially captured in the EPSA-NEMS analysis electricity demand used as inputs for this analysis.

\subsubsection{Fuel Prices}

ReEDS endogenously models the dynamics between delivered natural gas prices and power sector consumption (Eurek et al. 2016); however, this representation requires an initial fuel price projection as a starting point. In both Base Case and Advanced Technology Case sets of scenarios, we use fuel prices directly or indirectly derived from the AEO 2015 High Oil \& Gas 
Resource (HOGR) Case. ${ }^{17}$ For all Base Case scenarios, including all $\mathrm{CO}_{2}$ price scenarios, we rely on the same underlying initial natural gas prices directly from the AEO 2015 HOGR Case. We rely on distinct initial natural gas price projections for each of the Advanced Technology Case scenarios with initial fuel prices from the corresponding Advanced Technology Case $\mathrm{CO}_{2}$ price scenario from the EPSA-NEMS analysis, which modeled how economy-wide natural gas consumption and, therefore price, change under different $\mathrm{CO}_{2}$ prices. The EPSA-NEMS analysis also relied on assumptions from the AEO 2015 HOGR Case to represent the underlying fossil fuel resource. Coal and uranium prices are from the AEO 2016 Reference Case in all scenarios.

\subsubsection{Policies}

All cases model electric-sector policies current as of April 1, 2016, inclusive of policies such as state renewable portfolio standards, federal tax credits, and the Clean Power Plan (CPP). ${ }^{18} \mathrm{We}$ acknowledge that there are significant uncertainties with respect to future policies, especially in relation to the CPP. As shown below in Section 3, the CPP only has a measurable effect in one of our scenarios (Base Case without a $\mathrm{CO}_{2}$ price) and, as such, removal of the CPP regulations in these scenarios would have minimal to no impact. We discuss the implications and interactions with the CPP in Section 3.

\subsection{Key Caveats and Limitations}

The ReEDS model was chosen for this analysis as it is designed to specifically address the key issues related to clean energy technologies, particularly renewable energy technologies. It models the U.S. electricity system using high spatial resolution and applies statistical methods to represent the integration challenges with increasing renewable penetration levels. Because of these strengths, ReEDS has been used in several clean energy and renewable energy studies. ${ }^{19}$ As with any model, there are important limitations and caveats associated with ReEDS. Some of the key ones, along with others as outlined in the model documentation (Eurek et al. 2016), include the system-wide optimization framework of ReEDS and its lack of representation of manufacturing, supply chain, and siting. As a result of these limitations, ReEDS may not fully capture non-economic decision making or constraints to new infrastructure development, particularly in the near term. In addition, the system-wide optimization framework used by ReEDS does not capture revenue sufficiency requirements for individual generators or other electricity market effects on existing and new generators. Nonetheless, ReEDS uses highresolution modeling that provides a self-consistent framework to compare the economic competitiveness and deployment potential of a wide suite of power generation options.

\footnotetext{
${ }^{17}$ Although ReEDS has the capability to use base fuel prices from more-recent AEO cases, such as was done for the 2016 Standard Scenarios report, we use the AEO 2015 HOGR Case in this analysis to be consistent with the NEMSEPSA analysis. That work was originally developed before the AEO 2016 natural gas assumptions were available. For most projection years, natural gas prices from the AEO 2015 HOGR Case are similar to those in the AEO 2016 Reference Case.

${ }^{18}$ In this analysis the CPP is modeled as a mass-based standard with new source complement and with national trading. Although the CPP sets emissions targets from 2022 to 2030, we assume in our analysis that the target remains constant at the 2030 level for all years beyond 2030.

${ }^{19}$ Recent examples of studies using ReEDS include Bloom et al. 2016; Cole, Bepper et al. 2016; Cole, Mai et al. 2016; DOE 2012; DOE 2015; DOE 2016b; Mai, Cole et al. 2016; Mai, Lantz et al. 2016; and NREL 2012.
} 
In addition to the modeling limitations, there are a number of other important considerations regarding this analysis. As with the EPSA-NEMS analysis, this work projects the impact of a specific set of input assumptions but does not constitute a forecast. Nor is it a prediction of what outcomes would arise from specific RDD\&D investments in energy technologies. This is an analysis of the impact of specific exogenous assumptions around technology improvements and their interaction with hypothetical $\mathrm{CO}_{2}$ policies. We only model two sets of technology improvement projections that do not capture all possibilities. For example, a recent expert elicitation of wind energy costs (Wiser, Jenni et al. 2016) and recent new PV cost goals from the DOE Solar Energy Technologies Office (DOE 2016e) are not reflected in the analysis. We also do not model sensitivities to fuel prices, demand, and other important driving factors that could substantially alter scenario results.

Similarly, it is impossible to predict which specific technology breakthroughs or advancements will or will not occur. This analysis does not try to assess the likelihood of achieving any specific technology cost and performance target and only represents one possible scenario of RDD\&D outcomes in the power sector, based off of inputs derived from the set of DOE Technology Office goals. In particular, the Advanced Technology Case assumes improvements in all modeled clean generation technologies at the levels described above. Uncertainties in RDD\&D outcomes and impacts along with how innovations diffuse into markets are not addressed. As the above factors are all important for policy-makers (see Bistline 2016), the results should not be used to imply prioritization of technology RDD\&D activities and investments.

We do not attempt to examine each technology's deployment potential in isolation, which would impact the projected electricity generation mix. ${ }^{20}$ Therefore, any specific technology outcomes in this analysis should not be considered a bounding result. For example, if cost reductions in nuclear occur in the absence of renewable generation improvements, more nuclear generation could be expected than what is estimated in these results. Additional research using a moreexpansive set of scenarios would be needed to explore these and other dynamics that are outside the scope of our analysis.

${ }^{20}$ Mai, Lantz et al. (2016) model scenarios with multiple different wind power cost projections. 


\section{Results}

Figure 3 presents broad shifts in the U.S. electricity generation mix resulting from the different sets of technology and $\mathrm{CO}_{2}$ price scenarios modeled in our analysis. Figure 4 shows differences in generation by technology type between the Advanced Technology Case and Base Case. ${ }^{21}$ Comparing the Advanced Technology and Base Cases without a $\mathrm{CO}_{2}$ price, it is evident that renewable generation shows increased growth with the assumed RDD\&D advances. This growth, coupled with reduced electricity demand resulting from the increased deployment of energy efficiency technologies, displaces primarily natural gas generation and secondarily coal generation. The addition of $\mathrm{CO}_{2}$ prices maintains this general trend, but has the effect of decreasing the absolute differences in renewable generation between the Base Case and the Advanced Technology Case. Natural gas also accounts for the largest generation difference between the Advanced Technology Case and the Base Case, highlighting its projected role as the marginal generation source. Regardless of technology or $\mathrm{CO}_{2}$ price assumptions, nuclear generation is not significantly affected and coal generation sees declines from current levels in all scenarios. These trends are explored more in-depth on a technology-by-technology basis below.

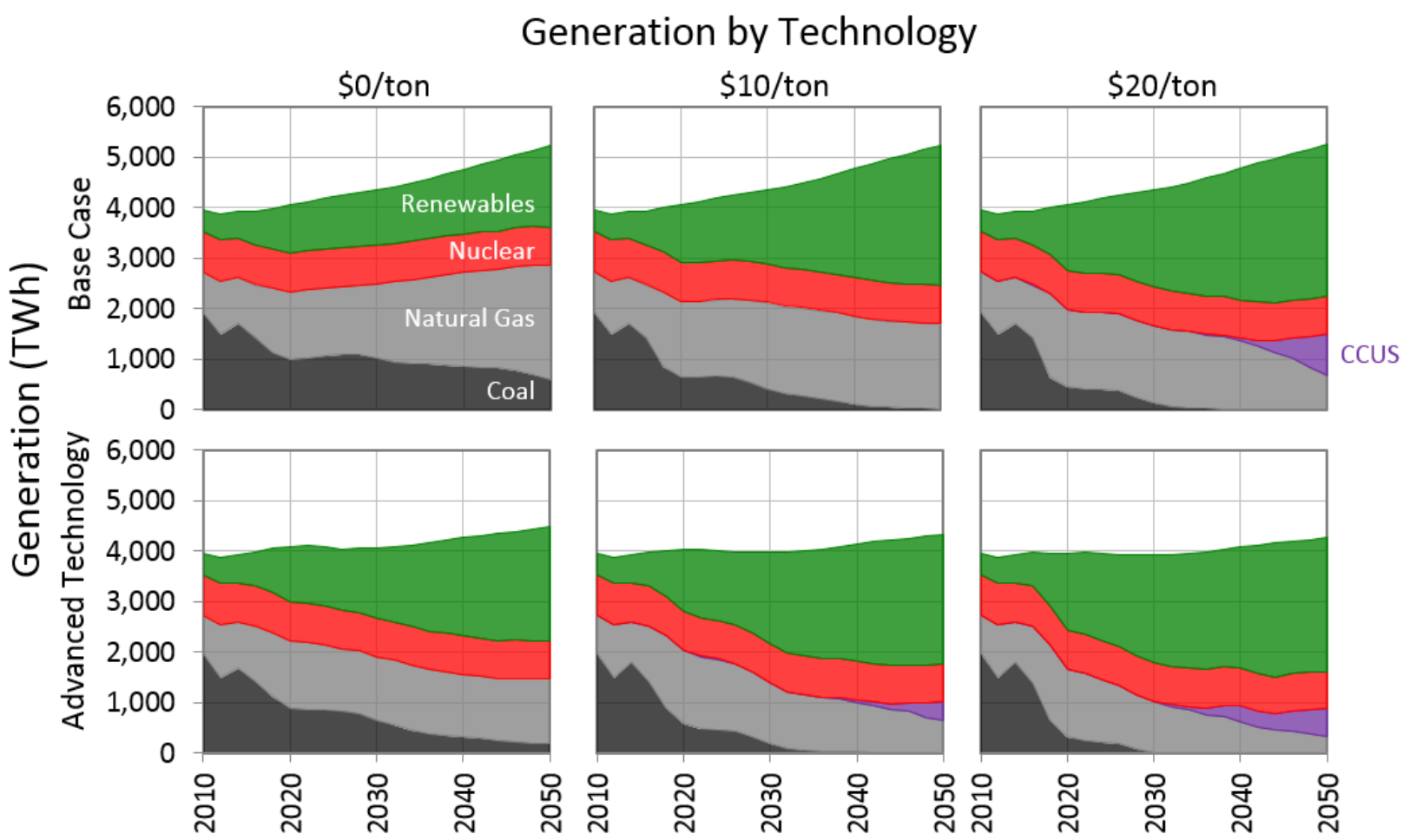

Figure 3. Generation by technology category under Base Case (top row) and Advanced Technology (bottom row) scenarios, under $\$ 0 /$ ton (left), $\$ 10$ (center), and $\$ 20 /$ ton (right) initial carbon prices, showing renewables (green), nuclear (red), CCUS (purple), natural gas (gray), and coal (black) generation sources

Data for historical years are based on model results, which align closely but not precisely with actual historical generation.

\footnotetext{
${ }^{21}$ Technology groupings in all figures are as follows: "Coal" includes coal-fired generation and minor contributions from oil and gas steam plants; "Natural Gas" includes generation from combined-cycle and single-cycle combustion turbine units; "Renewables" include generation from solar (both utility and distributed photovoltaic and CSP), wind, hydropower, geothermal, and biomass.
} 


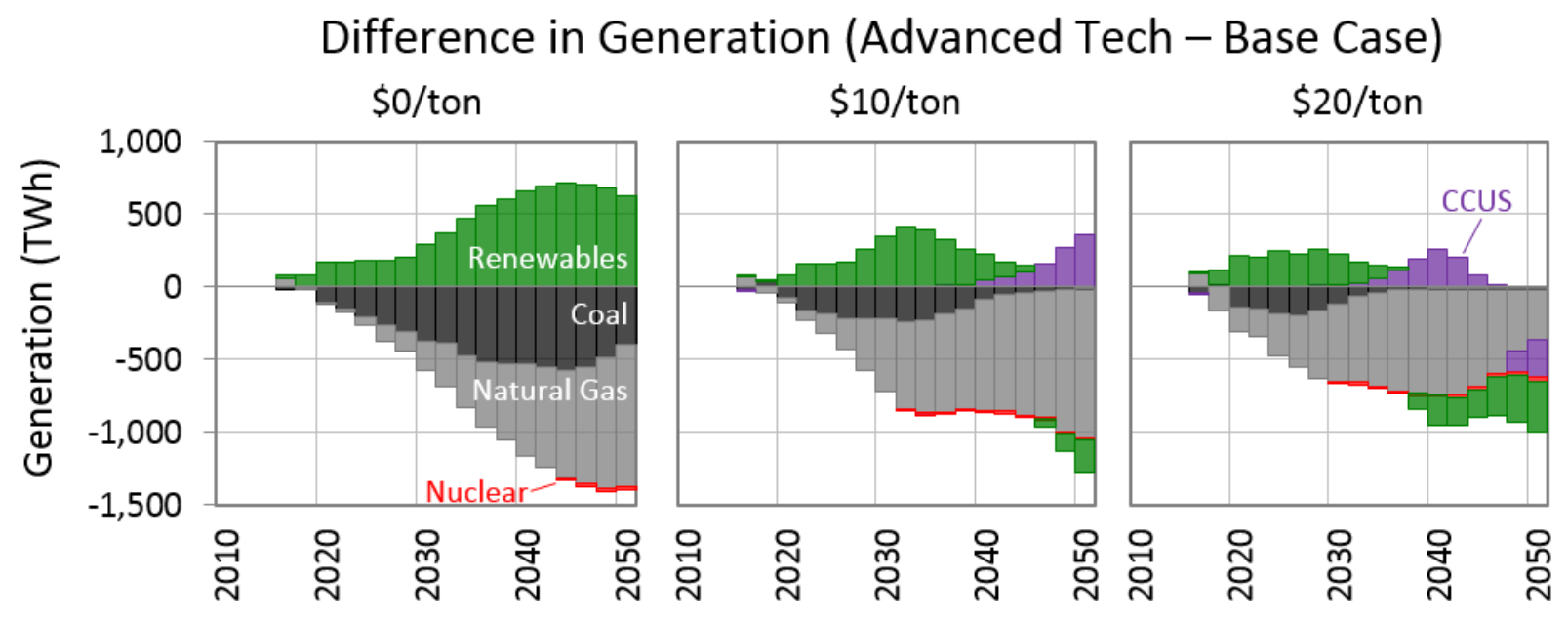

Figure 4. Difference in generation between the Advanced Technology Case and the Base Case by technology category, under $\$ 0 /$ ton (left), $\$ 10$ (center), and $\$ 20 /$ ton (right) initial carbon prices, showing renewables (green), nuclear (red), CCUS (purple), natural gas (gray), and coal (black) generation sources

Bars above zero indicate more generation in the Advanced Technology Case while bars below zero indicate more generation in the Base Case.

\subsection{Renewable Generation}

The amount of renewable generation ${ }^{22}$ has been growing in recent years and reached $13.8 \%$ of total generation in 2015 (DOE 2016a). In all of the scenarios modeled, renewable generation grows substantially and represents a significant portion of the total generation mix by 2050 , as seen in Figure 3 and Figure 5. The vast majority of this projected growth is due to increased deployment from solar PV and land-based wind power. Prior studies (e.g., Cole, Mai et al. 2016; Mai, Lantz et al. 2016) have shown that relative growth between renewable technologies, including between wind and solar technologies, can be highly sensitive to cost assumptions but that they have similar emission reductions and displace similar mixes of non-renewable generation (Wiser, Mai et al. 2016; DOE 2015). As such, and because we do not attempt to project specific technology breakthroughs, we report all renewable generation as a single category.

In the absence of a carbon price, the Advanced Technology Case achieves greater renewable generation than the Base Case. In the near term, both scenarios see increased renewable generation, as seen in Figure 5. These amounts represent renewable generation shares of $25 \%$ and $34 \%$ for the Base Case and Advanced Technology Case scenarios, respectively. ${ }^{23}$ Near-term renewable energy growth in both scenarios is driven partly by the investment tax credit (ITC) for solar power and the production tax credit (PTC) for wind power that were extended in 2015 and are scheduled to phase out or phase down by 2022 and 2020, respectively. ${ }^{24}$ Supported by these

\footnotetext{
${ }^{22}$ Renewable generation is defined as generation from land-based and off-shore wind, distributed and utility-scale photovoltaic, concentrating solar power, geothermal, hydropower, and biopower.

${ }^{23}$ We define generation shares as a percent of total generation, where total generation includes distributed generation.

${ }^{24}$ The solar ITC drops to $10 \%$ after 2021 for commercial facilities and to $0 \%$ for residential facilities based on current legislation. The wind PTC expires completely after 2019.
} 
tax credits and the relatively lower costs of wind and solar compared to other renewable technologies, land-based wind and solar PV technologies account for the majority of the growth in renewables in the near-term in both cases. The lower cost and improved performance of wind and solar assumed in the Advanced Technology Case also drives increased growth compared to the Base Case even after the tax credits expire.

The scenarios begin to diverge more significantly over the long-term (2030-2050). The Base Case shows moderate growth in renewable generation, reaching 1,626 TWh generation in 2050 (31\% of total generation) whereas the Advanced Technology Case reaches 2,250 TWh (50\%) in 2050. While both scenarios achieve higher levels of renewable generation, only the $50 \%$ generation share in the Advanced Technology Case is within the range of 33\%-59\% projected in the 2016 Standard Scenarios set of results (Cole, Mai et al. 2016). ${ }^{25}$
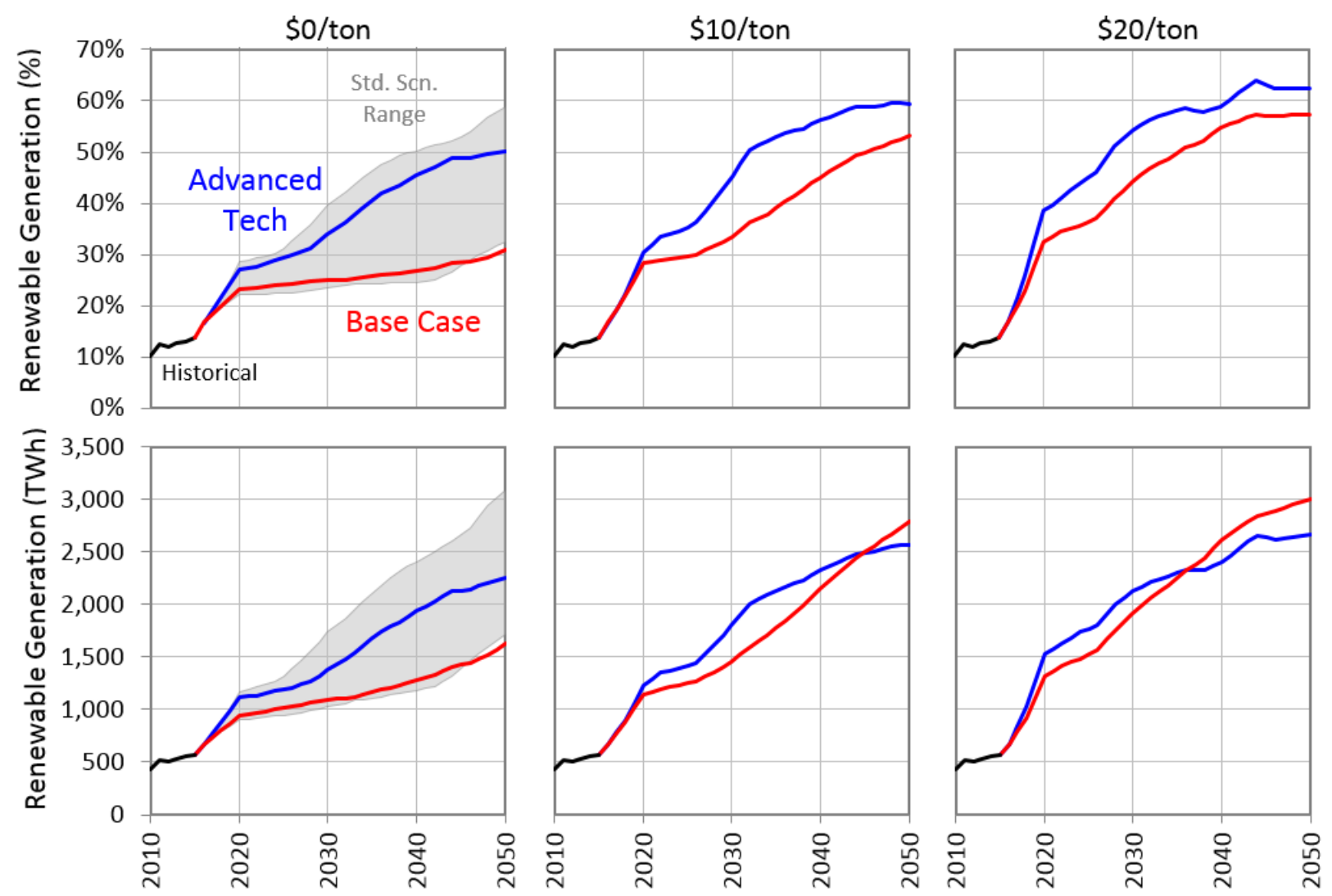

Figure 5. Modeled power sector renewable generation (bottom) and generation share (top) under Base Case (red) and Advanced Technology Case (blue) scenarios, with \$0/ton (left), \$10/ton (middle), and \$20/ton (right) initial $\mathrm{CO}_{2}$ prices

The range of renewable generation associated with the scenarios in the 2016 Standard Scenarios report that explore a range of assumed future technology costs, fuel prices, and electricity demand is shown in gray. Historical generation from EIA is shown in black.

\footnotetext{
25 The generation share in the Base Case falls outside of the Standard Scenarios range due to the extended nuclear lifetime assumptions in our analysis and the different natural gas price assumptions.
} 
The addition of $\mathrm{CO}_{2}$ prices has the effect of decreasing the differences in renewable generation between the two sets of technology assumptions. An initial $\$ 10 /$ ton $\mathrm{CO}_{2}$ price has a large impact on renewable generation in the Base Case, increasing generation from 1,626 TWh (31\%) to $2,795 \mathrm{TWh}(53 \%)$ in 2050. This is similar to the 2,570 TWh (59\%) in the Advanced Technology Case with the same initial $\$ 10$ /ton $\mathrm{CO}_{2}$ price. Increasing the initial $\mathrm{CO}_{2}$ price to $\$ 20 /$ ton results in limited further renewable generation and market share increases over the $\$ 10 /$ ton $\mathrm{CO}_{2}$ price for both technology cases; projected 2050 renewable generation shares fall within a narrow range $(52 \%-62 \%)$ under both technology cases with $\mathrm{CO}_{2}$ price scenarios.

With $\mathrm{CO}_{2}$ prices, the Base Case results in renewable generation that is slightly in excess of that found in the Advanced Technology Case by 2050 (bottom row of Figure 5). However, the 2050 renewable generation share in the Base Case is still less than that of the Advanced Technology Case (top row of Figure 5). This results from differences in electricity demand between the two scenarios, as the Advanced Technology Case assumes lower electricity consumption, largely due to the increased performance and deployment of energy efficiency technologies. With lower demand for electricity, there is less room for growth for new generation. In addition, lower demand growth requires potential new capacity to compete with lower-cost options, for example, more efficient units or existing facilities with depreciated costs as opposed to new capacity from conventional generation.

These results highlight how renewables, primarily land-based wind and solar PV generation can be economically competitive with new and existing conventional sources of generation, particularly with the technology advancements assumed in our analysis. Significant and roughly equal amounts of renewable generation growth are observed with either a $\$ 10 /$ ton initial carbon price (in the Base Case) or increased cost and performance through RDD\&D investments (in the Advanced Technology Case without a $\mathrm{CO}_{2}$ price). By 2050, renewable energy in the Advanced Technology Case achieves a $50 \%$ generation share without a $\mathrm{CO}_{2}$ price while the Base Case with an initial $\$ 10 /$ ton $\mathrm{CO}_{2}$ price results in a $53 \%$ renewable generation share.

Renewable generation shares also tend to plateau in the long term, as there are diminishing returns for both improved cost and performance of renewable technologies and increasing $\mathrm{CO}_{2}$ prices. In both sets of technology assumptions, growth in renewable generation share slows after 2030 ; shares approach about $60 \%$ by 2050 . The slow or flat growth in renewable generation share likely results from a number of factors that could increase the cost or decrease the value of renewable energy, particularly wind and solar: ${ }^{26}$

- Resource supply limits and locations. Although the technical potential for renewable resources (e.g., wind and solar) far exceeds annual electricity needs (Lopez et al. 2012), the highest quality renewable resources in a given location are constrained. ${ }^{27}$ With increasing renewable energy deployment, such as found in many of our scenarios, greater reliance on

\footnotetext{
${ }^{26}$ The ReEDS model used in our analysis is designed to account for many of these factors (Eurek et al. 2016). For example: ReEDS models regional renewable resource constraints for each of its 134 or 356 model regions; accounts for interconnection and long-distance transmission expansion and costs; calculates marginal capacity value, curtailments, and increased operating reserves in its investment and dispatch decisions; and estimates changing avoided generation costs implicitly in its reduced-form dispatch modeling.

${ }^{27}$ Regional resource constraints are applicable to all energy sources, but the inability to transport the renewable "fuel" in most cases makes this factor particularly relevant to renewable energy.
} 
higher cost or lower performance (e.g., lower capacity factor) sites can be required. Moreover, some of the highest-quality renewable energy resources are located far from regions where electricity demand is greatest thereby requiring transmission expansion to connect supply with demand regions. These factors contribute to an increasing cost of supply for renewable capacity that, with increasing renewable deployment, could result in higher costs than other non-renewable sources.

- Variability in renewable electricity production. The majority of the growth in renewable generation found in our scenarios is from wind and solar PV, which have variable production output due to their reliance on meteorological conditions. This variability or nondispatchability presents technical challenges when integrating increasingly high shares of renewable generation into the electricity system. In particular, renewable energy production may not be well-correlated with the highest value hours (e.g., when demand is greatest) thereby reducing electric system operators' ability to avoid utilization of the most operationally costly units. With increasing renewable generation shares - and absent mitigation to increase system flexibility (Cochran et al. 2014) - the value of renewable generation can decline due to this variability. ${ }^{28}$

- Uncertainty in renewable electricity production. The weather-dependent nature of wind and solar generation also causes imperfect predictability in their generation output. To accommodate for this increased uncertainty, system operators typically require higher operating reserve requirements thereby - all else being equal-increasing the cost of operating a system. ${ }^{29}$ Improved variable generation forecasting practices can help to reduce these incrementally higher operating reserve costs (Orwig et al. 2015).

These factors contribute to the slowing of the growth in renewable generation shares; however, absolute renewable generation continues to grow at roughly the same pace as demand growth (Figure 5). Although none of the scenarios find renewable generation shares to significantly exceed $60 \%$, this does not represent an upper limit for renewable generation. ${ }^{30}$ On the other hand, while much research on renewable grid integration has found the technical feasibility of integrating up to about 30\%-33\% wind and solar energy (e.g., Bloom et al. 2016; Lew et al. 2013), more-limited research exists beyond these levels. ${ }^{31}$ In our scenarios, further demand for electricity capacity is met with other sources that could enable increased electric system flexibility such as natural gas or CCUS, as discussed in the sections below. ${ }^{32}$

\footnotetext{
${ }^{28}$ Renewable curtailment-renewable energy that is available but cannot be utilized by the system due to the mismatch of renewable production and system needs - provides a straight-forward example of reduced renewable value at high penetrations (Denholm et al. 2015). Even in the absence of curtailment, the non-dispatchability and correlated profiles of renewable energy can lead to the displacement of lower-cost thermal generators as renewable generation shares increase. Declining renewable capacity value provides another example of decreasing value with increasing renewable shares in the planning context (Cochran et al. 2015).

${ }^{29}$ To be clear, the uncertainty of wind and solar can increase operating reserve costs but since wind and solar have zero-marginal operating costs, total production costs are typically lower with increase renewable deployment.

${ }^{30}$ For example, NREL (2012) explores scenarios with up to $80 \%-90 \%$ renewable generation share.

${ }^{31}$ Notable exceptions include Brinkman (2015), Brinkman et al. (2016), Jorgenson et al. (2017), and MacDonald et al. (2016).

${ }^{32}$ Although ReEDS does endogenously model storage technologies, another potential source of system flexibility, the cost of storage was not varied between the Base and Advanced Technology Cases, due to limitations in the inputs derived from the EPSA-NEMS analysis. If lower-cost storage were available it might enable higher renewable generation shares in our scenarios.
} 
Overall, significant growth in renewable generation is observed in all scenarios, and renewable generation has the potential to become the largest source of generation with technology advancements and/or $\mathrm{CO}_{2}$ prices. The technology advancement scenario without a $\mathrm{CO}_{2}$ price results in the greatest difference between the Base Case and Advanced Technology Case, and achieves as much renewable generation as the Base Case with a $\$ 10 /$ ton initial $\mathrm{CO}_{2}$ price. The addition of $\mathrm{CO}_{2}$ prices also tend to reduce the impact of technology advancements on renewable deployment, as both sets of technology assumptions result in renewables plateauing after reaching significant generation levels.

While the overall trends in renewable generation growth are consistent between these results and the EPSA-NEMS study, there are a few notable differences. The Advanced Technology Case from our analysis results in nearly 600 TWh more renewable generation by 2040 as compared to the EPSA-NEMS Advanced Technology Case under all three $\mathrm{CO}_{2}$ price scenarios, mostly from additional wind and solar generation. This is likely due to the lower input assumptions used in this study for wind (see Section 2) along with differences in how the two models treat integration challenges and solutions of high levels of variable renewable generation. Future work is needed to more-fully understand the causes of these differences.

\subsection{CCUS and Nuclear}

The other major clean energy technologies considered in the analysis are carbon capture utilization and sequestration (CCUS) and nuclear. Both are typically large-capacity facilities that can provide dispatchable low-emissions generation, in contrast to the variable wind and solar generation discussed in Section 3.1. Nuclear is an established technology that currently provides approximately $20 \%$ of the nation's electricity supply and over $60 \%$ of the carbon-free electricity generation, whereas CCUS is an emerging technology that has not yet seen wide-spread deployment in the power sector. ${ }^{33}$

Expansion of nuclear capacity in the United States occurred mostly in the 20-year timespan between 1970 and 1990, with little new development since. Some increases in nuclear capacity have occurred recently primarily as a result of capacity uprates at existing facilities rather than construction of new facilities. There are a number of new nuclear-generating units planned to begin operation within the next few years (EIA 2016c). However, since 2010 there have been a number of announced retirements of nuclear facilities ahead of their operating license expiration (EIA 2016d). The net effect of this is that nuclear-generating capacity is projected to remain largely constant in the near term (EIA 2016a).

\footnotetext{
${ }^{33}$ The Kemper County Energy Facility is the only CCUS plant in the United States nearing operation. It is a coal plant designed to capture at least $65 \%$ of $\mathrm{CO}_{2}$ emissions (Mississippi Power n.d.).
} 

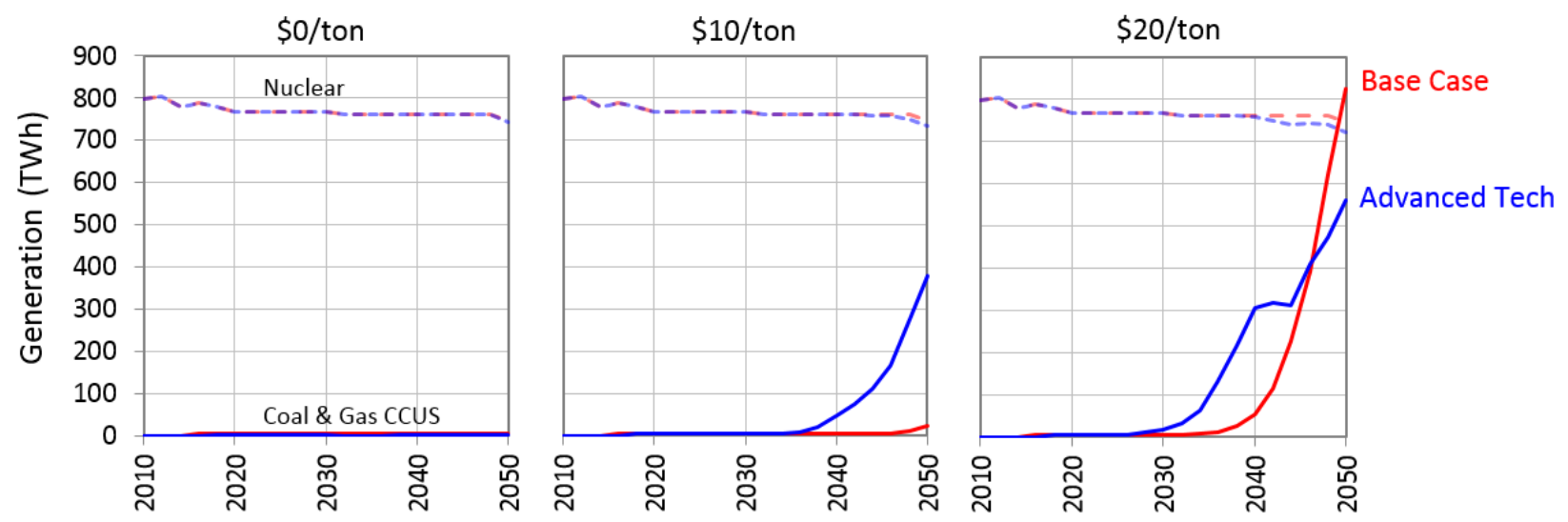

Figure 6. Modeled power sector nuclear (top, dashed) and coal and gas CCUS (bottom, solid) generation Base Case (red) and Advanced Technology Case (blue) generation cost and performance assumptions, with $\$ 0 /$ ton (left), $\$ 10 /$ ton (middle), and $\$ 20 /$ ton (right) initial $\mathrm{CO}_{2}$ prices

The majority of new CCUS is from natural gas CCUS generation.

Both the assumed improvement in the cost and performance of nuclear facilities and the addition of $\mathrm{CO}_{2}$ prices have minimal impact on nuclear generation, as seen in Figure 6, with generation remaining essentially constant across all scenarios. This outcome is a consequence of new nuclear having a relatively higher cost than new natural gas or renewable capacity even with technology improvements in the Advanced Technology Case. These findings suggest that there would likely need to be technology improvements beyond that explored in the Advanced Technology Case, additional subsidies or other policy measures, more-limited improvements in other generation technologies compared to what we assumed, higher electricity demand growth, or some combination thereof for significant expansion of nuclear capacity to occur under the conditions modeled.

CCUS deployment is projected after 2030 in both the Base and Advanced Technology Cases when $\mathrm{CO}_{2}$ prices are assumed, as seen in Figure 6. An initial $\$ 10 /$ ton $\mathrm{CO}_{2}$ price coupled with the Advanced Technology Case drives growth of CCUS generation to nearly 400 TWh by 2050. Increasing to an initial $\$ 20 /$ ton $\mathrm{CO}_{2}$ price is sufficient to drive substantial growth in the Base Case as well, reaching over 800 TWh by 2050. While both coal and natural gas have CCUS options, the majority of CCUS that is built in these scenarios is natural gas CCUS. Base Case technology assumptions coupled with an initial \$20/ton $\mathrm{CO}_{2}$ price projects the highest level of CCUS generation by 2050 of all the scenarios explored. This outcome is a result of the higher electricity demand growth in the Base Case than in the Advanced Technology Case, resulting in greater demand for electricity generation. 
Both nuclear and CCUS technologies are potentially large sources of low-carbon generation. However, the availability of low-cost renewable generation with low-cost natural gas generation in the Advanced Technology Case, coupled with lower demand growth, reduces the need for new nuclear and CCUS deployment in the absence of a $\mathrm{CO}_{2}$ price. While the addition of $\mathrm{CO}_{2}$ prices can drive new CCUS generation, it is not sufficient to drive additional nuclear capacity. This analysis does not explore other scenarios that might drive more demand for nuclear or CCUS technologies. For example, increased electricity demand from expanded electrification of energy end-uses (e.g., electric vehicles, electric heat pumps) beyond what is modeled, the representation of additional potential revenue streams for nuclear and CCUS facilities, ${ }^{34}$ or nuclear and CCUS cost and performance breakthroughs that could occur in the absence of other generation and efficiency technology advancements, might result in increased deployment. ${ }^{35}$

These findings are mostly consistent with the EPSA-NEMS analysis, which finds that without a carbon price there is limited additional generation from either nuclear or CCUS technologies. However, the EPSA-NEMS analysis does find significant new nuclear generation by 2040 with initial $\$ 10$ /ton and $\$ 20 /$ ton $\mathrm{CO}_{2}$ prices in the Advanced Technology Case, on the order of 100 to $250 \mathrm{TWh}$, respectively. The lower amounts of renewable generation in the EPSA-NEMS analysis would create greater opportunities for other zero- or low-emitting technologies, such as nuclear, when a carbon policy is assumed.

\subsection{Natural Gas Generation}

Advances in hydraulic fracturing and horizontal drilling technologies have resulted in a significant supply of low-priced natural gas that has impacted the electric sector substantially over the last decade. For example, average capacity factors of natural gas combined cycles increased from 35\% in 2005 to 56\% in 2015 (EIA 2016b). Natural gas has surpassed coal as the largest source of U.S. generation in the first eight months of 2016 (EIA 2016e; EIA 2016h). As shown in Figure 7, the NREL 2016 Standard Scenarios results generally showed that absent strong $\mathrm{CO}_{2}$ emissions policies or unexpected increases in natural gas prices, natural gas generation is projected to grow over the long term (Cole, Mai, et. al 2016).

\footnotetext{
${ }^{34}$ For example, we do not include potential thermal energy production from nuclear facilities or $\mathrm{CO}_{2}$ for enhanced oil recovery for CCUS facilities.

${ }^{35}$ To explore one representation of the potential magnitude of this last effect, we modeled a sensitivity which used Advanced Technology Case assumptions for all generation technologies except for renewable generation technologies (left at Base Case assumptions), along with a $\$ 10 /$ ton initial $\mathrm{CO}_{2}$ price. This increased $2050 \mathrm{CCUS}$ generation from nearly $400 \mathrm{TWh}$ in Figure 5 to over $800 \mathrm{TWh}$, and decreased renewable generation from approximately 2,500 TWh down to 2,000 TWh. There was no effect on nuclear generation. This indicates that with a $\mathrm{CO}_{2}$ price, deployment results are sensitive to CCUS and renewable relative costs.
} 

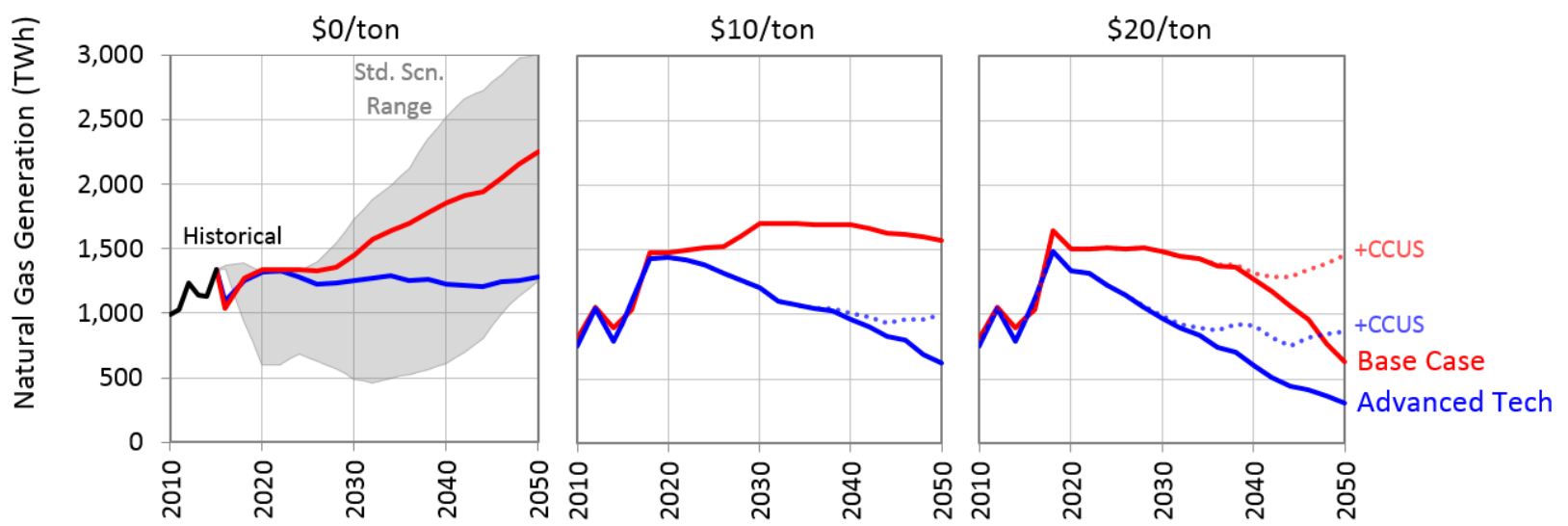

Figure 7. Modeled power sector natural gas generation for the Base Case (red) and Advanced Technology Case (blue) scenarios, under \$0/ton (left), \$10/ton (middle), and \$20/ton (right) initial carbon prices. Dotted lines add natural gas CCUS generation

The range of natural gas generation associated with the scenarios in the 2016 Standard Scenarios report that explore a range of assumed future technology costs, fuel prices, and electricity demand is shown in gray.

Assumed improvements in other generation technologies is found to reduce natural gas (without CCUS) generation in this analysis. Results from the Base Case with no $\mathrm{CO}_{2}$ price generally follow the trend observed in the set of NREL 2016 Standard Scenarios of long-term growth, increasing steadily from 1,300 TWh in 2015 to 2,250 TWh in 2050, representing the largest source of generation at $43 \%$ by 2050 (Figure 7). ${ }^{36}$ The Advanced Technology Case results in a nearly constant amount of natural gas generation, maintaining at approximately 1,300 TWh through 2050. With the same natural gas (without CCUS) cost and performance projection used in the Base Case and the Advanced Technology Case scenarios, but with more significant RDD\&D-driven cost reductions for renewable technologies coupled with reduced electricity demand growth in the Advanced Technology Case, natural gas generation is projected to be lower for all Advanced Technology Cases relative to the Base Case, as seen in Figure 7.

Natural gas generation responds to the addition of $\mathrm{CO}_{2}$ prices as seen in Figure 7, and can drive a transition from natural gas without CCUS to natural gas with CCUS generation. Implementation of an initial $\$ 10 /$ ton $\mathrm{CO}_{2}$ price results in a plateauing of generation around 1,500 TWh by 2050 in the Base Case and steady decrease to 620 TWh in 2050 in the Advanced Technology Case. As noted previously, this outcome is primarily a consequence of the expansion of low-cost renewable generation in these scenarios. A further increase in $\mathrm{CO}_{2}$ price to an initial \$20/ton results in reductions in 2050 natural gas (without CCUS) generation to $630 \mathrm{TWh}$ and $310 \mathrm{TWh}$ in the Base Case and Advanced Technology Case, respectively. These deeper reductions in natural gas generation are replaced by growth in natural gas CCUS generation. As shown in Figure 7, when natural gas CCUS generation is accounted for, natural gas generation remains nearly constant in the long term (2030-2050) regardless of either $\mathrm{CO}_{2}$ policy examined.

\footnotetext{
${ }^{36}$ The Base Case natural gas generation differs slightly in the short term from the 2016 Standard Scenarios set as it uses gas prices from the AEO 2015 High Oil and Gas Resource scenario and the 2016 Standard Scenarios use gas prices from the AEO 2016 Reference Case. In the long term, differences also arise as a result of differences in fuel prices and nuclear retirement assumptions.
} 
Overall, regardless of technology improvements or $\mathrm{CO}_{2}$ emissions policies, natural gas is projected to be a significant source of electricity generation out to 2050. In addition, natural gas capacity provides a range of grid services independent of projected trends in natural gas generation. For example, the fast dispatch capability of natural gas-fired units, along with projected continued low fuel costs enable natural gas to complement an electricity system with higher proportions of variable wind and solar generation. In other words, natural gas provides additional flexibility to help support the integration of variable renewable energy. Natural gas technology's lower $\mathrm{CO}_{2}$ emissions rate (compared with coal without CCUS) and potential to employ CCUS technologies enable it to play a substantial role under policy-constrained $\mathrm{CO}_{2}$ emissions scenarios (Cole, Beppler et al. 2016). However, absent successful RDD\&D in natural gas CCUS technologies or with natural gas fuel prices increasing faster than portrayed by our assumptions, future natural gas deployment might be more limited than is projected in our scenarios. On the other hand, lower natural gas prices or more improved CCUS costs than assumed in our scenarios could yield even larger opportunities for new natural gas capacity and generation.

The natural gas generation trajectories presented here agree with the findings in the EPSANEMS study, both showing limited natural gas growth in both Advanced Technology Case and in both technology cases with $\mathrm{CO}_{2}$ prices.

\subsection{Electricity System Cost}

The impact of assumed RDD\&D-driven technology improvement scenarios on total power sector system cost are estimated in this section. The system cost metric calculated from ReEDS represents the present value, using a 3\% real discount rate, ${ }^{37}$ of all electric system expenditures from 2015 to 2050, inclusive of capital, O\&M, and fuel expenditures for existing and new generation, transmission, and storage. The ReEDS-reported system cost reflects expenditures in aggregate for the entire contiguous U.S. electricity system and do not inform how costs might be allocated to or passed on to different utilities, load-serving entities, or consumers. ${ }^{38}$ In addition, as described previously, the ReEDS model employs a nationwide optimization framework, which tends to result in lower-cost decision making than region-oriented or distributed, multiagent decision making approaches applied in utility planning and procurement. As a consequence, estimated systems costs are likely lower than actual costs in all scenarios. ${ }^{39}$ Finally, we also note that this metric does not include the impacts of federal renewable tax credits or other energy subsidies, investment costs associated with underlying energy efficiency and electrification assumptions, or investment costs associated with RDD\&D programs. ${ }^{40}$ For this analysis, we estimate some of these additional costs separately as presented below.

\footnotetext{
37 The 3\% discount rate used for our system cost metric represents a social discount rate, which differs from the higher discount rate (5.3\% real, weighted average cost of capital) used for the ReEDS investment and dispatch decision making. A 3\% discount rate is also in line with guidance from the White House Office of Management and Budget for "cost-effectiveness" analysis that spans multiple decades.

${ }^{38}$ ReEDS also include electricity price estimates, but these are not reported for this study due to the significant deviations to electricity end-use consumption as a result of the EPSA-NEMS analysis.

${ }^{39}$ See Eurek et. al. (2016) for a more complete description of the system cost metric as implemented in ReEDS.

${ }^{40}$ As explained earlier, the consequences of the latter two are simply reflected in the exogenous demand growth and technology cost and performance assumptions used in our scenarios. Investment costs associated with these actions are not captured directly within ReEDS and its system cost metric.
} 
Figure 8 summarizes the system cost output of the ReEDS model for the Base Case and Advanced Technology Case scenarios without a $\mathrm{CO}_{2}$ price. We only focus on the cases without a $\mathrm{CO}_{2}$ price as we do not estimate the cost of implementing, collecting, or distributing the revenues, of $\mathrm{CO}_{2}$ price policy. When focusing only on costs that are directly calculated in ReEDS and shown in Figure 8, the Advanced Technology Case results in reduced system costs of $\$ 393$ billion relative to the Base Case. The majority of the savings result from reduced conventional fuel expenditures (mostly related to coal and natural gas fuels), enabled by lowercost renewable generation and through reduced demand via assumed deployment of energy efficiency technologies. ${ }^{41}$

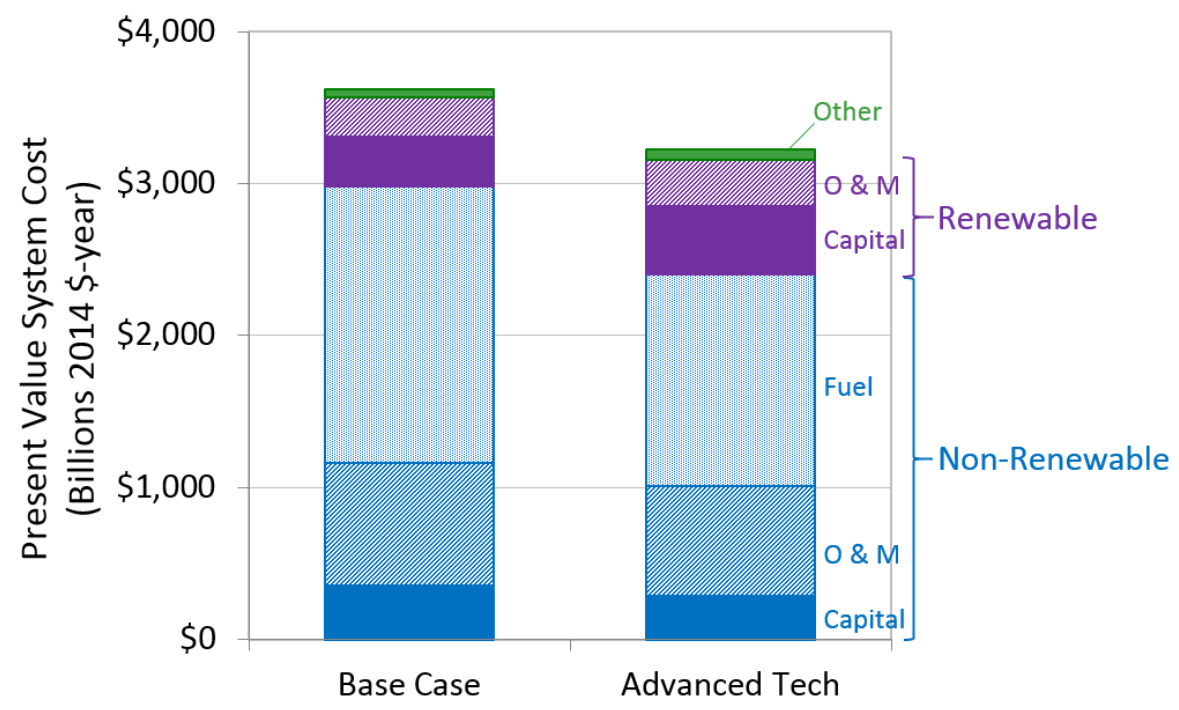

Figure 8. Present value of total system costs output from ReEDS from 2015 through 2050, discounted at 3\%, in the Base Case and the Advanced Technology Case

The "other" category includes capital and operating costs associated with the deployment and operation of storage, transmission, thermal cooling equipment and other water-related costs.

Although the system costs presented in Figure 8 include all direct electricity system expenditures associated with the scenarios, they do not include all costs that one might consider to morecomprehensively compare scenarios given the different exogenous demand growth and technology cost assumptions used in the Base and Advanced Technology Cases. For an informed comparison, it is important to understand the scope of the cost metric presented here: System costs from Figure 8 exclude energy efficiency program spending to support decreased electricity demand or other expenditures that influence electricity end-use demand. The reported system costs also do not include the impacts of federal renewable energy tax credits or subsidies for other energy sources such as fossil fuels and nuclear energy. As ReEDS only models bulk power system-level infrastructure (e.g., high-voltage transmission), the system costs also exclude costs

\footnotetext{
41 To attempt to separate out the impact of each of these factors, we also examined the total system costs of a side scenario where the Advanced Technology Case generation cost and performance assumptions were applied with the Base Case electricity demand. This sensitivity scenario resulted in system costs reduced by $\$ 138$ billion (4\%) relative to the Base Case, indicating that while the majority of cost savings come from reduced demand due to energy efficiency, a significant amount of savings do arise from expanded renewable generation.
} 
for distribution system infrastructure. ${ }^{42}$ Reported system costs do not include investments in RDD\&D activities needed to achieve either the Base Case or the Advanced Technology Case technology cost and performance projections. Moreover, this analysis does not consider additional potential sources of benefits, such as reductions in air pollutants such as $\mathrm{SO}_{2}, \mathrm{NO}_{\mathrm{x}}$, and particulate matter, reduction in water withdrawal and consumption, or potential reductions of expenditures for natural gas use outside the electric sector. Recent assessments of the magnitude of some of these potential impacts have shown significant monetized benefits resulting from increased renewable generation, in particular (Mai, Wiser et al. 2016; Wiser, Mai et al. 2016; Wiser, Barbose et al. 2016; DOE 2015; DOE 2016b).

While we do not attempt to assess all of these additional elements, we do estimate potential costs associated with two factors - renewable tax credits and energy efficiency program spending that might most-consequentially reduce the $\$ 393$ billion in savings identified in the Advanced Technology Case relative to the Base Case. Under our assumptions and calculations, the incremental present value of already-authorized tax credits and energy efficiency program spending from 2015 to 2050 would reduce the savings by $\$ 84$ billion to $\$ 309$ billion. ${ }^{43}$ In other words, even when considering additional potential costs associated with federal renewable tax incentives and energy efficiency, the technology improvement assumed in the Advanced Technology Case is estimated to result in an electricity system that is $\$ 309$ billion less costly in present-value terms than the Base Case. Further research is needed to incorporate estimates for other excluded elements so that a more-comprehensive comparison of costs can be made between the two cases.

\subsection{Power Sector Emissions}

Emissions from the power sector have been declining over the past decade, falling to 1,919 MMT $\mathrm{CO}_{2}$ in 2015, a decline of $21 \%$ since 2005 (EIA 2016f). This emissions reduction has been driven by a number of factors, including low natural gas prices resulting in a displacement of coal generation with natural gas generation, a significant amount of coal capacity retirements, increasing generation from zero emission renewable energy technologies such as wind and solar power, and energy efficiency measures and a recovering economy leading to low or negative growth in electricity consumption (EIA 2016g). Projected low natural gas prices, as assumed in our analysis, through at least the near term suggest that this reduced-emissions trend is likely to continue. In the longer term, power sector $\mathrm{CO}_{2}$ emissions may be capped by the $\mathrm{CPP}$, which is estimated to reduce power sector emissions to $32 \%-35 \%$ below 2005 levels by 2030 (EPA 2015b; EIA 2016i). However, this estimate is heavily dependent on future fuel prices, electricity demand, compliance options, and other generation technology cost and performance assumptions. In addition, legal challenges and other uncertainties with respect to the CPP exist. These uncertainties coupled with the potential for new state or federal clean energy policies further complicate projections of future U.S. power sector emissions. While acknowledging these uncertainties, we present the power sector emissions results from our scenario analysis.

\footnotetext{
42 The system costs do include the capital and O\&M costs associated with distributed rooftop PV, but not any upgrades or maintenance of distribution-level networks that might be necessary to support increased amounts of distributed PV generation or vehicle electrification.

${ }^{43}$ The methods and assumptions for calculating these factors are presented in the Appendix.
} 

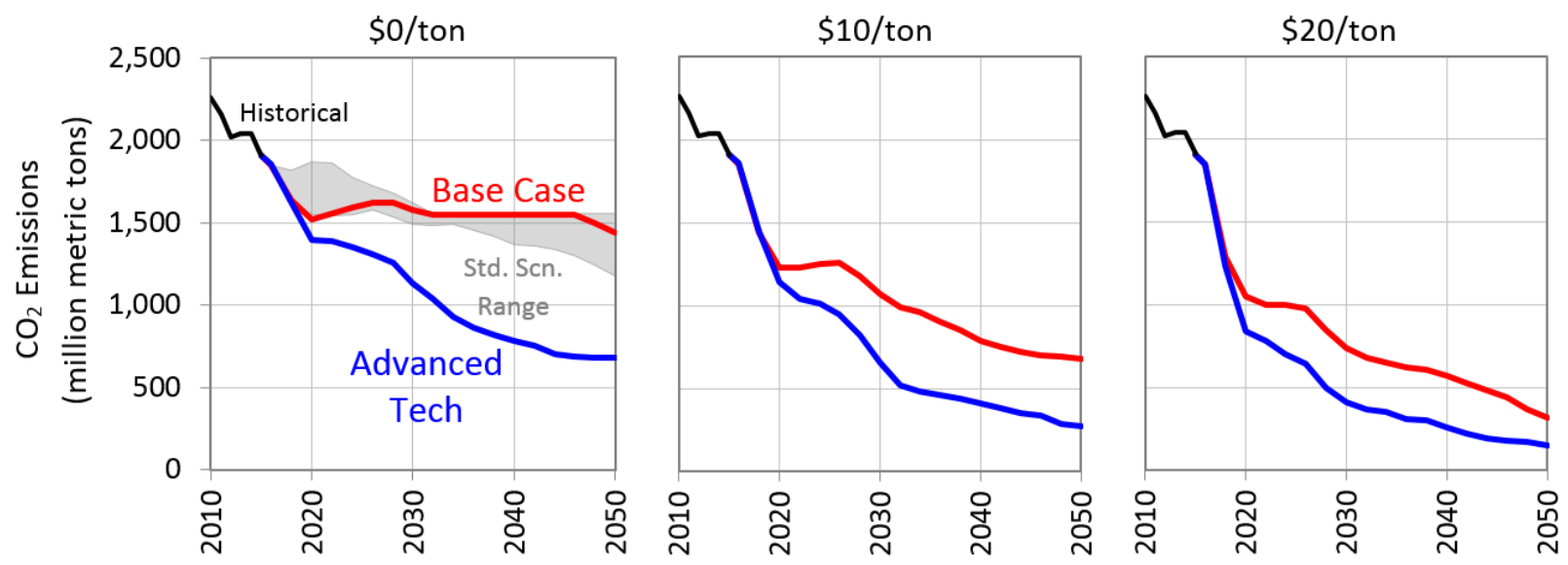

Figure 9. Modeled power sector $\mathrm{CO}_{2}$ emissions under Base Case (red) and Advanced Technology Case (blue) scenarios, along with initial $\mathrm{CO}_{2}$ emissions prices of $\$ 0$ (left), $\$ 10$ (center), and $\$ 20$ (right) per metric ton

The range of emissions associated with the scenarios in the 2016 Standard Scenarios report that explore a range of assumed future technology costs, fuel prices, and electricity demand is shown in gray.

As shown in Figure 9, the Base Case results in annual $\mathrm{CO}_{2}$ emissions that decline to about 1,500 MMT by 2020 and stays roughly flat from then on. The near-term emissions decline is driven in large part by new renewable generation supported by the federal renewable tax credits and continued coal-to-gas fuel switching (Mai, Cole et al. 2016). Emissions in the Base Case rise during the early 2020s primarily as a result of rising natural gas prices, which enable coal generation to regain generation share at the expense of natural gas generation, along with the expiration of the federal tax credits slowing the growth in new renewable generation. After this period, total power sector emissions are bound by the CPP limits assumed in our analysis. By 2044, emissions fall below those targets set forth by the CPP, driven by assumed age-based coal plant retirements and greater utilization of lower-emitting generation sources like natural gas and renewables.

In our analysis, the Base Case (without $\mathrm{CO}_{2}$ price) is the only scenario where the CPP affects generation or emissions results. As will be discussed below, in all other scenarios the assumed clean energy technology cost reductions, $\mathrm{CO}_{2}$ price, or both are found to reduce emissions below the CPP emissions levels. This suggests that our findings do not hinge on the CPP - and would in fact be greater if we were to exclude the CPP. ${ }^{44}$ Notwithstanding that result, the CPP provides a ceiling on emissions (or emission rates) in the absence of successful technology advancements or $\mathrm{CO}_{2}$ pricing that are not assured. In addition, the CPP is found to help lower Base Case emissions to well below historical levels as shown in Figure 9.

The Advanced Technology Case results in significant reductions of $\mathrm{CO}_{2}$ emissions relative to the Base Case throughout all time frames. Power sector emissions are near 1,200 MMT $\mathrm{CO}_{2}$ by 2030, which is already well below the Base Case and NREL 2016 Standard Scenarios range of emissions as seen in Figure 9. Power sector emissions in the Advanced Technology Case reach

\footnotetext{
${ }^{44}$ Without the CPP, the Base Case (without $\mathrm{CO}_{2}$ price) would result in higher emissions than estimated here; differences in emissions would be greater between this scenario and the others.
} 
$680 \mathrm{MMT} \mathrm{CO}_{2}$ in 2050 , a $72 \%$ reduction compared to 2005 levels. These results are a culmination of all the factors discussed earlier in the technology generation results: expansion of renewable generation due to lower cost and improved performance, reduction in electricity demand due to energy efficiency technology improvements and adoption, and reductions in coal (without CCUS) generation and assumed coal retirements.

The addition of $\mathrm{CO}_{2}$ prices shows two notable results. The first is that the emissions reductions due to RDD\&D success in the Advanced Technology Case are roughly equivalent to the reductions achieved in the Base Case with an initial $\$ 10 /$ ton $\mathrm{CO}_{2}$ price. The former achieves $72 \%$ reduction and the latter $74 \%$ reductions in emissions from 2005 levels by 2050 (Table 2). The second is that there are diminishing returns for emissions reductions from increases in $\mathrm{CO}_{2}$ prices, particularly in the Advanced Technology Case. The highest reductions in $\mathrm{CO}_{2}$ emissions occur between the Base Case and the Advanced Technology Case without a $\mathrm{CO}_{2}$ price, resulting in emissions reductions relative to 2005 of $40 \%$ and $72 \%$ respectively by 2050 . The addition of a $\$ 10 /$ ton initial $\mathrm{CO}_{2}$ price reduces that difference to $74 \%$ and $89 \%$ respectively. A carbon price is found to reduce differences in power sector emissions between the Base Case and the Advanced Technology Case. This outcome is likely due to the rising cost of marginal sources of emissions reductions.

Table 2. Projected 2050 Power Sector $\mathrm{CO}_{2}$ Emissions Reductions relative to 2005

\begin{tabular}{llll}
\hline Scenario & $\mathbf{\$ 0 / t o n}$ & $\mathbf{\$ 1 0 / \text { ton }}$ & $\mathbf{\$ 2 0 / \text { ton }}$ \\
\hline Base Case & $40 \%$ & $74 \%$ & $88 \%$ \\
Advanced Tech & $72 \%$ & $89 \%$ & $94 \%$ \\
\hline
\end{tabular}

The Base Case is estimated to result in $40 \% \mathrm{CO}_{2}$ emissions reductions from 2005 levels by 2050 , which is within the range of $35 \%-51 \%$ reported in the 2016 Standard Scenarios (Cole, Mai et al. 2016). This level of reduction is not sufficient to reach the decarbonization level needed to avoid the worst impacts of climate change as suggested by the Intergovernmental Panel on Climate Change and others (IPCC 2014; Rogelj et al. 2015). The Advanced Technology Case set of assumptions results in greater decarbonization levels ( $72 \%$ below 2005 levels by 2050 ) and well above the 2030 level targeted in the CPP. However there are a number of caveats to consider. The Advanced Technology Case results are only considering effects on the power sector and not on the wider economy. This analysis does not consider other significant factors that would affect power sector evolution and economy-wide emissions trajectories such as increased electrification of transportation through electric vehicle adoption or further improvements in energy efficiency (e.g., fuel economy standards). The economy-wide emissions trajectory resulting from Advanced Technology Case assumptions (without $\mathrm{CO}_{2}$ prices) is unlikely to be sufficient to reach economy-wide deep decarbonization by 2050 without additional policies (DOE 2017).

While overall trends and drivers of power sector $\mathrm{CO}_{2}$ emissions trajectories estimated from the scenarios are consistent with the findings of the EPSA-NEMS analysis, this analysis results in lower power sector $\mathrm{CO}_{2}$ emissions. Our analysis results in 2040 power sector $\mathrm{CO}_{2}$ emissions that are 650, 235, and 190 million metric tons lower than the EPSA-NEMS analysis results for the Advanced Technology Case with $\$ 0 /$ ton, $\$ 10 /$ ton, and $\$ 20 /$ ton initial $\mathrm{CO}_{2}$ prices respectively. These differences likely result from factors that influence the different generation mixes as discussed previously. In particular, this analysis has higher amounts of renewable generation 
( $\sim 650 \mathrm{TWh}$ in 2040 with $\$ 0 /$ ton initial $\mathrm{CO}_{2}$ price) as compared to the EPSA-NEMS analysis, whereas the EPSA-NEMS analysis has approximately equal amounts of coal generation from existing coal facilities leading to greater projected $\mathrm{CO}_{2}$ emissions compared with emissions from our scenarios.

\section{Summary}

Further improvements in energy technologies enabled by RDD\&D activities have the potential to significantly impact the future portfolio of electricity generating technologies, and also can reduce overall power system costs, and substantially reduce power sector $\mathrm{CO}_{2}$ emissions.

With the Advanced Technology Case assumptions, RDD\&D-related improvements can accelerate the growth of new renewable generation such that renewable energy technologies provide the majority of electricity demand by 2050, both with and without additional $\mathrm{CO}_{2}$ emissions policies. However, the advancements assumed for CCUS and nuclear technologies are not alone sufficient to result in significant new growth. Either further policy support, more aggressive technology advancements, or less competition from renewable generation, are likely needed to support significant new generation from these technologies by 2050 .

Natural gas remains a significant source of electricity generation regardless of the RDD\&D related technology advancements in other generating sources or $\mathrm{CO}_{2}$ policy scenario. While technology improvements in renewables generally displace increasing generation natural gas over the long term, the natural gas generation remains mostly constant without additional $\mathrm{CO}_{2}$ policies. Natural gas generation without CCUS tends to decrease by 2050 with additional $\mathrm{CO}_{2}$ policies, but this is found to be partially mitigated by increasing generation from natural gas with CCUS technologies, in scenarios both with and without advanced technology assumptions.

In general, we estimate that achieving RDD\&D-enabled technology improvements alone without any additional $\mathrm{CO}_{2}$ prices would result in significant savings of about $\$ 393$ billion in total direct power sector costs through 2050. Considering potential additional costs associated with federal renewable tax credits and energy efficiency is estimated to reduce these savings to a still sizable amount of about \$309 billion. However, we do not account for the cost of RDD\&D investments or for other environmental, health, and economic benefits.

Finally, we find that RDD\&D technology advancement can continue the recent historical trend of power sector $\mathrm{CO}_{2}$ emissions reductions, and has the potential to achieve emissions well below 2005 levels, even in the absence of additional policy measures.

While these findings represent only one possible future of clean energy technology innovation, future work in this area could explore the impact of advances of each technology in isolation, and with a wider range of sensitivities in assumptions of fuel prices and electricity demand. This would provide a set of results that could better define the range of possible impacts of energy technology innovations, and highlight the potential role of each individual technology. In addition, a broader evaluation of costs and benefits would provide a more comprehensive set of metrics to evaluate the impact of successful energy technology improvements from RDD\&D investment. 


\section{References}

Bistline, John. 2016. "Energy Technology R\&D Portfolio Management: Modeling Uncertain Returns and Market Diffusion.” Applied Energy. Vol 183, 1181-1196.

http://dx.doi.org/10.1016/j.apenergy.2016.09.062

Bloom, Aaron, Aaron Townsend, David Palchak, Joshua Novacheck, Jack King, Clayton Barrows, Eduardo Ibanez, Matthew O'Connell, Gary Jordan, Billy Roberts, Caroline Draxl, and Kenny Gruchalla. 2016. Eastern Renewable Generation Integration Study. Golden, CO: National Renewable Energy Laboratory. NREL/TP-6A20-64472.

http://www.nrel.gov/docs/fy16osti/64472.pdf.

Brinkman, Gregory. 2015. Renewable Electricity Futures: Operational Analysis of the Western Interconnection at Very High Renewable Penetrations. Golden, CO: National Renewable Energy Laboratory. NREL/TP-6A20-64467. http://www.nrel.gov/docs/fy15osti/64467.pdf.

Brinkman, Gregory, Jennie Jorgenson, Ali Ehlen, and James H. Caldwell. 2016. Low Carbon Grid Study: Analysis of a 50\% Emission Reduction in California. Golden, CO: National Renewable Energy Laboratory. NREL/TP-6A20-64884.

http://www.nrel.gov/docs/fy16osti/64884.pdf.

Cochran, Jaquelin, Paul Denholm, Bethany Speer, and Mackay Miller. 2015. Grid Integration and the Carrying Capacity of the U.S. Grid to Incorporate Variable Renewable Energy. Golden, CO: National Renewable Energy Laboratory. NREL/TP-6A20-62607. http://www.nrel.gov/docs/fy15osti/62607.pdf.

Cochran, Jaquelin, Mackay Miller, Owen Zinaman, Michael Milligan, Doug Arent, Bryan Palmintier, Mark O’Malley, Simon Mueller, Eamonn Lannoye, Aidan Tuohy, Ben Kujala, Morten Sommer, Hannele Holttinen, Juha Kiviluoma, and S.K. Soonee. 2014. Flexibility in $21^{\text {st }}$ Century Power Systems. Golden, CO: National Renewable Energy Laboratory. NREL/TP-6A206a721. http://www.nrel.gov/docs/fy14osti/61721.pdf.

Cole, Wesley, Ross Beppler, Owen Zinaman, and Jeffrey Logan. 2016. Considering the Role of Natural Gas in the Deep Decarbonization of the U.S. Electricity Sector. Golden, CO: National Renewable Energy Laboratory. NREL/TP-6A50-64654.

http://www.nrel.gov/docs/fy16osti/64654.pdf.

Cole, Wesley, Trieu Mai, Jeffrey Logan, Daniel Steinberg, James McCall, James Richards, Benjamin Sigrin, and Gian Porro. 2016. 2016 Standard Scenarios Report: A U.S. Electricity Sector Outlook. Golden, CO: National Renewable Energy Laboratory. NREL.TP-6A20-66939. http://www.nrel.gov/docs/fy16osti/66939.pdf.

DOE (U.S. Department of Energy). 2010a. Retrospective Benefit-Cost Evaluation of U.S. DOE Wind Energy R\&D Program: Impact of Selected Technology Investments. Prepared by Delta Research Co., Evanston, IL. https://energy.gov/sites/prod/files/2015/05/f22/wind bc report1014-10.pdf. 
2010b. Retrospective Benefit-Cost Evaluation of DOE Investment in Photovoltaic Energy Systems. Prepared by RTI International, Research Triangle Park, NC. https://energy.gov/sites/prod/files/2015/05/f22/solar_pv.pdf.

2012. SunShot Vision Study. Washington, DC: U.S. Department of Energy. DOE/GO102012-3037. https://energy.gov/eere/sunshot/sunshot-vision-study.

- 2015. Wind Vision: A New Era for Wind Power in the United States. Washington, DC: U.S. Department of Energy. DOE/GO-102015-4557.

http://www.energy.gov/sites/prod/files/WindVision_Report_final.pdf.

- 2016a. 2015 Renewable Energy Data Book. Washington, DC: U.S. Department of Energy. DOE/GO-102016-4904. http://www.nrel.gov/docs/fy17osti/66591.pdf.

- 2016b. Hydropower Vision: A New Chapter for America's $1^{\text {st }}$ Renewable Electricity Source. Washington, DC: U.S. Department of Energy. DOE/GO-102016-4869. https://energy.gov/sites/prod/files/2016/10/f33/Hydropower-Vision-10262016 0.pdf.

- 2016c. "Shale Research and Development." Office of Fossil Energy. Accessed December 28. https://energy.gov/fe/science-innovation/oil-gas-research/shale-gas-rd.

- 2016d. "SunShot Initiative Goals." Office of Energy Efficiency and Renewable Energy. Accessed December 28. https://energy.gov/eere/sunshot/sunshot-initiative-goals.

- 2016e. The SunShot Initiative's 2030 Goal: $3 \phi$ per Kilowatt Hour for Solar Electricity. Washington, DC; U.S. Department of Energy. DOE/EE-1501. https://energy.gov/sites/prod/files/2016/12/f34/SunShot $\% 202030 \% 20$ Fact $\% 20$ Sheet-12_16.pdf.

- 2017. Energy $\mathrm{CO}_{2}$ Emissions Impacts of Clean Energy Technology Innovation and Policy. Washington, DC: U.S. Department of Energy.

https://www.energy.gov/epsa/downloads/energy-co2-emissions-impacts-clean-energytechnology-innovation-and-policy

Denholm, Paul, Matthew O’Connell, Gregory Brinkman, and Jennie Jorgenson. 2015.

Overgeneration from Solar Energy in California: A Field Guide to the Duck Chart. Golden, CO: National Renewable Energy Laboratory. NREL/TP-6A20-65023.

http://www.nrel.gov/docs/fy16osti/65023.pdf

EIA (U.S. Energy Information Administration). 2016a. Annual Energy Outlook 2016. Washington, D.C.: Department of Energy. DOE/EIA-0383(2016).

- 2016a. "Coal Made up More than 80\% of Retired Electricity Generating Capacity in 2015." Today in Energy. March 18. http://www.eia.gov/todayinenergy/detail.php?id=25272.

- 2016b. "Average Utilization for Natural Gas Combined-Cycle Plants Exceeded Coal Plants in 2015." Today in Energy. April 4.

http://www.eia.gov/todayinenergy/detail.php?id=25652. 
- 2016c. "First New U.S. Nuclear Reactor in Almost Two Decades Set to Begin Operating." Today in Energy. June 14. https://www.eia.gov/todayinenergy/detail.php?id=26652.

- 2016d. "Fort Calhoun Becomes Fifth U.S. Nuclear Plant to Retire in Past Five Years." Today in Energy. October 31. https://www.eia.gov/todayinenergy/detail.php?id=28572.

_. 2016e. "Table 7.2a Electricity Net Generation.” Monthly Energy Review November 2016. Washington, D.C.: Department of Energy. http:/www.eia.gov/totalenergy/data/monthly/pdf/sec7 5.pdf.

- 2016f. "Table 12.6 Carbon Dioxide Emissions from Energy Consumption: Electric Power Sector." Monthly Energy Review November 2016. Washington, D.C.: Department of Energy. http://www.eia.gov/totalenergy/data/monthly/pdf/sec12 9.pdf.

- 2016g. "Carbon Dioxide Emissions from Electricity Generation in 2015 were Lowest Since 1993." Today in Energy. May 13.

https://www.eia.gov/todayinenergy/detail.php?id=26232.

- 2016h. "Natural Gas-Fired Electricity Generation Expected to Reach Record Level in 2016." Today in Energy. July 14. https:/www.eia.gov/todayinenergy/detail.php?id=27072.

- 2016i. "Future Power Sector Carbon Dioxide Emissions Depend on Status of Clean Power Plan." Today in Energy. May 18.

https://www.eia.gov/todayinenergy/detail.php?id=26292.

_. 2016j. Electric Power Monthly. December. Washington, D.C.: Department of Energy. http://www.eia.gov/electricity/monthly/.

EPA (U.S. Environmental Protection Agency. 2015a. Standards of Performance for Greenhouse Gas Emissions from New, Modified, and Reconstructed Stationary Sources: Electric Utility Generating Units. Washington, DC, https:/www.federalregister.gov/articles/2015/10/23/201522837/standards-ofperformance-for-greenhouse-gas-emissions-from-newmodifiedandreconstructed-stationary

- 2015b. Regulatory Impact Analysis for the Clean Power Plan Final Rule. Washington, D.C. https://www.epa.gov/sites/production/files/2015-08/documents/cpp-final-rule-ria.pdf.

Eurek, Kelly, Wesley Cole, David Bielen, Stuart Cohen, Bethany Frew, Jonathan Ho, Venkat Krishnan, Trieu Mai, and Daniel Steinberg. 2016. Regional Energy Deployment System (ReEDS) Model Documentation: Version 2016. Golden, CO: National Renewable Energy Laboratory. NREL/TP-6A20-67067. http://www.nrel.gov/docs/fy17osti/67067.pdf.

Hoffman, Ian M., Gregory M. Rybka, Greg Leventis, Charles A. Goldman, Lisa C. Schwartz, Megan A. Billingsley, and Steven R. Schiller. 2015. The Total Cost of Saving Electricity through Utility Customer-Funded Energy Efficiency Programs: Estimates at the National, State, Sector and Program Level. Berkeley, CA: Lawrence Berkeley National Laboratory.

https://emp.lbl.gov/sites/all/files/total-cost-of-saved-energy_0.pdf. 
IPCC (Intergovernmental Panel on Climate Change). 2014. Climate Change 2014: Mitigation of Climate Change: Working Group III Contribution to the Fifth Assessment Report of the IPCC. Cambridge, UK: Cambridge University Press.

Jorgenson, Jennie, Trieu Mai, and Greg Brinkman. 2017. Reducing Wind Curtailment through Transmission Expansion in a Wind Vision Future. Golden, CO: National Renewable Energy Laboratory. NREL/TP-6A20-67240. http://www.nrel.gov/docs/fy17osti/67240.pdf.

Lew, D., G. Brinkman, E. Ibanez, A. Florita, M. Heaney, B.-M. Hodge, M. Hummon, G. Stark, J. King, S.A. Lefton, N. Kumar, D. Agan, G. Jordan, and S. Venkataraman. 2013. The Western Wind and Solar Integration Study Phase 2. Golden, CO: National Renewable Energy Laboratory. NREL/TP-5500-55588. http://www.nrel.gov/docs/fy13osti/55588.pdf.

Lopez, Anthony, Billy Roberts, Donna Heimiller, Nate Blair, and Gian Porro. 2012. U.S. Renewable Energy Technical Potentials: A GIS-Based Analysis. Golden, CO:

National Renewable Energy Laboratory. NREL/TP-6A20-51946.

http://www.nrel.gov/docs/fy12osti/51946.pdf.

MIT (Massachusetts Institute of Technology). 2011. The Future of Natural Gas. Cambridge, MA: Massachusetts Institute of Technology Energy Initiative.

https://energy.mit.edu/research/future-natural-gas/

MacDonald, Alexander E., Christopher T. M. Clack, Anneliese Alexander, Adam Dunbar, James Wilczak, and Yuanfu Zie. 2016. "Future Cost-Competitive Electricity Systems and their Impact on US CO2 Emissions." Nature Climate Change 6:526-531.

Mai, Trieu, Wesley Cole, Eric Lantz, Cara Marcy, and Benjamin Sigrin. 2016. Impacts of Federal Tax Credit Extensions on Renewable Deployment and Power Sector Emissions. Golden, CO: National Renewable Energy Laboratory. NREL/TP-6A20-65571.

http://www.nrel.gov/docs/fy16osti/65571.pdf.

Mai, Trieu, Eric Lantz, Jonathan Ho, Tyler Stehly, and Donna Heimiller. 2016. Outlooks for Wind Power in the United States: Drivers and Trends under a 2016 Policy Environment. Golden, CO: National Renewable Energy Laboratory. NREL/TP-6A20-67058. http://www.nrel.gov/docs/fy16osti/67058.pdf.

Mai, Trieu, Ryan Wiser, Galen Barbose, Lori Bird, Jenny Heeter, David Keyser, Venkat Krishnan, Jordan Macknick, and Dev Millstein. 2016. A Prospective Analysis of the Costs, Benefits, and Impacts of U.S. Renewable Portfolio Standards. NREL/TP-6A20-67455/LBNL1006962. Golden, CO and Berkeley, CA: National Renewable Energy Laboratory and Lawrence Berkeley National Laboratory. http://www.nrel.gov/docs/fy17osti/67455.pdf.

Mississippi Power, "Kemper County Energy Facility: Quick Facts.” n.d. Mississippi Power, About Energy. Accessed December 22, 2016. http://www.mississippipower.com/aboutenergy/plants/kemper-county-energy-facility/facts

NREL (National Renewable Energy Laboratory). 2012. Renewable Electricity Futures Study. Hand, M.M.; Baldwin, S.; DeMeo, E.; Reilly, J.M.; Mai, T.; Arent, D.; Porro, G.; Meshek, M.; 
Sandor, D. eds. 4 vols. NREL/TP-6A20-52409. Golden, CO: National Renewable Energy Laboratory. http://www.nrel.gov/analysis/re futures/.

— 2016. "2016 Annual Technology Baseline.” National Renewable Energy Laboratory. http://www.nrel.gov/analysis/data tech baseline.html.

Orwig, Kirsten D., Mark L. Ahlstrom, Venkat Banunarayanan, Justin Sharp, James M. Wilczak, Jeffrey Freedman, Sue Ellen Haupt, Joel Cline, Obadiah Bartholomy, Hendrik F. Hamann, BriMathias Hodge, Catherine Finley, Dora Nakafuji, Jack L. Peterson, David Maggio, and Melinda Marquis. 2015. "Recent Trends in Variable Generation Forecasting and Its Value to the Power System." IEEE Transactions on Sustainable Energy 6(3): 924-933. doi.org/10.1109/TSTE.2014.2366118.

Rogelj, Joeri, Gunnar Luderer, Robert C. Pietzcker, Elmar Kriegler, Michiel Schaeffer, Volker Krey, and Keywan Riahi. 2015. "Energy System Transformations for Limiting End-of-Century Warming to below $1.5^{\circ} \mathrm{C}$." Nature Climate Change 5(6):519-27. doi:10.1038/nclimate2572.

Sigrin, Benjamin, Michael Gleason, Robert Preus, Ian Baring-Gould, and Robert Margolis. 2016. The Distributed Generation Market Demand Model (dGen): Documentation. Golden, CO: National Renewable Energy Laboratory. NREL/TP-6A20-65231. http://www.nrel.gov/docs/fy16osti/65231.pdf.

Wiser, R., G. Barbose, J. Heeter, T. Mai, L. Bird, M. Bolinger, A. Carpenter, G. Heath, D. Keyser, J. Macknick, A. Mills, and D. Millstein. 2016. A Retrospective Analysis of the Benefits and Impacts of U.S. Renewable Portfolio Standards. Lawrence Berkeley National Laboratory and National Renewable Energy Laboratory. NREL/TP-6A20-65005. http://www.nrel.gov/docs/fy16osti/65005.pdf.

Wiser, Ryan, Karen Jenni, Joachim Seel, Erin Baker, Maureen Hand, Eric Lantz, and Aaron Smith. 2016. "Expert Elicitation Survey on Future Wind Energy Costs." Nature Energy 1(16135, September 2016). doi:10.1038/nenergy.2016.135.

Wiser, Ryan, Trieu Mai, Dev Millstein, Jordan Macknick, Alberta Carpenter, Stuart Cohen, Wesley Cole, Bethany Frew, and Garvin A. Heath. 2016. On the Path to SunShot: The Environmental and Public Health Benefits of Achieving High Penetrations of Solar Energy in the United States. Golden, CO: National Renewable Energy Laboratory. NREL/TP-6A20-65628. http://www.nrel.gov/docs/fy16osti/65628.pdf.

Woodhouse, Michael, Rebecca Jones-Albertus, David Feldman, Ran Fu, Kelsey Horowitz, Donald Chung, Dirk Jordan, and Sarah Kurtz. 2016. On the Path to SunShot: The Role of Advancements in Solar Photovoltaic Efficiency, Reliability, and Costs. Golden, CO: National Renewable Energy Laboratory. NREL/TP-6A20-65872. http://www.nrel.gov/docs/fy16osti/65872.pdf. 


\section{Appendix}

This appendix describes the methods and assumptions used to calculate the difference in present value costs of federal tax credits and energy efficiency between the Base Case and Advanced Technology Case. As described in the report, other factors might need to be considered for a more-complete assessment of costs. Nonetheless, we estimate these two factors to understand how they might alter the direct electric system cost comparisons between these two cases.

\section{Tax Credits}

The present value cost of the already-authorized renewable tax credits are estimated for increased wind and solar deployment, which represents the majority of renewable deployment differences between the Base Case and Advanced Technology Case scenarios.

\section{Production Tax Credit}

The PTC for wind power is $\$ 23 / \mathrm{MWh}$ for projects that began construction before 2017 , and it ramps down to $80 \%, 60 \%$, and $40 \%$ of that value for wind projects beginning construction in 2017,2018 , and 2019 respectively, before expiring fully in 2020. For purposes of this estimate, the incremental amount of additional wind generation for a given year is assumed to have begun construction two years prior. ${ }^{45}$ Therefore, new incremental generation in 2016 through 2018 receives $100 \%$ PTC value, and new incremental generation in 2019, 2020, and 2021 receive $80 \%, 60 \%$, and $40 \%$ respectively.

The incremental generation is multiplied by the appropriate PTC value to calculate the annual PTC cost for new generation installed in a given year. That annual cost is assumed to repeat exactly in real terms for 10 years. All PTC cash flows are converted to present value costs using a $3 \%$ discount rate.

\section{Investment Tax Credit}

The current value of the ITC for solar power is $30 \%$ of installation costs, falling to $26 \%$ and $24 \%$ for projects that have begun construction by 2020 and 2021, respectively, and applies to all solar technologies including CSP, utility-scale PV, and distributed PV. Commercially owned systems also continue to receive a $10 \%$ ITC after 2021 while the ITC expires fully for residential owners. Each year's incremental capacity is multiplied by the solar technology's respective capital cost for that year from the Annual Technology Baseline for each scenario's respective cost trajectory (ATB Mid-Case for the Base Case and ATB Low-Case for the Advanced Technology Case) (NREL 2016). Each year's incremental new capacity is assumed to have begun construction in the prior year, so new capacity in 2020 receives the 30\% ITC, while new capacity in 2021 and 2022 receive the $26 \%$ and $24 \%$ value respectively, and new capacity in 2023 and after receives the $10 \%$ ITC. The annual ITC costs are converted to a present value using a 3\% discount rate.

\footnotetext{
${ }^{45}$ For new wind capacity we model an effective three-year construction period instead of a two-year period. IRS guidance allows for a four-year safe harbor; however, given that the construction period for most plants has been two years or less, we conservatively assumed three years in our tax credit representation in ReEDS. For utility-scale solar, we assume a two-year construction period. Smaller-scale solar facilities are assumed to have construction periods of one year or less.
} 


\section{Energy Efficiency Programs}

The Advanced Technology Case results in significantly reduced electricity demand over the Base Case. This is a result of increased RDD\&D yielding more energy efficient end-use technologies, reducing market barriers, and programs that increase adoption of these technologies. It is difficult to assess the amount of demand reduction that occurs from additional energy efficiency program spending by utilities and other energy efficiency groups versus how much would be adopted in the absence of these programs. The system costs presented in Figure 8 assume that demand reductions occur exogenous to the power sector and so exclude any energy efficiency program spending. Here, we attempt to estimate an upper bound on the additional costs that could result due to energy efficiency program spending in the Advanced Technology Case relative to the Base Case.

First, we subtract the total electricity generation in the Advanced Technology Case from the Base Case to calculate the reduced demand for each year in the 2016-2050 time period. The amount of reduced generation is multiplied by $\$ 47.6 / \mathrm{MWh}$, which is the total program and participant cost estimate of saved energy based on a review of energy efficiency programs across the nation (Hoffman, Rybka et al. 2015). We assume these costs escalate 3\% annually (in real terms). This is a conservative assumption to account for the possibility that energy efficiency program costs would rise (in real terms) over time if reducing the marginal unit of electricity demand becomes more difficult. In other words, this is a conservative assumption to account for the possibility that the $\$ 47.6 / \mathrm{MWh}$ cost of saved energy is not representative of future, potentially more expensive to achieve, energy efficiency measures. The sum of the cost stream is then used as a conservative estimate of energy efficiency program expenditures relative to the Base Case.

\section{Summary}

Using these estimation methods and assumptions, we find that incremental costs between the Base Case and Advanced Technology Case to be $\$ 28$ billion for federal tax credits, $\$ 57$ billion for additional energy efficiency program, and $\$ 84$ billion for both together. Table A-1 summarizes these results.

Table A-1. Upper Bound Estimates of Present Value for Additional Costs in the Advanced Technology Case Relative to the Base Case, 2015-2050 (billions, 2014 dollars)

\begin{tabular}{ll}
\hline Cost Category & Difference \\
\hline Solar and wind, ITC and PTC & $\$ 28$ \\
Additional energy efficiency programs & $\$ 57$ \\
\hline Total & $\$ 84$ \\
\hline
\end{tabular}

